\title{
Multi-component microscale biosynthesis of unnatural cyanobacterial indole alkaloids
}

Yogan Khatri ${ }^{\varnothing \xi}$, Robert M Hohlman ${ }^{\varnothing \xi}$, Johnny Mendoza ${ }^{\Delta}$, Shasha $\mathrm{Li}^{\varnothing \xi}$, Andrew N. Lowell ${ }^{\varnothing}$, Haruichi Asahara\&, and

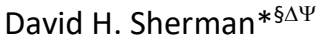

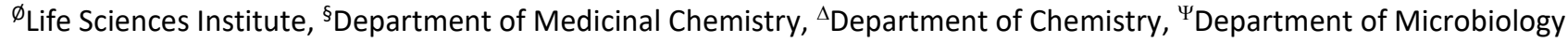
and Immunology, University of Michigan, Ann Arbor, Michigan 48109

\&New England Biolabs, Inc., 240 County Road, Ipswich, MA 01938 


\section{Supplemental Data}

\section{Supplemental Table}

Table S1: Assigned numeral representation for the synthetic substrates, prenyltransferase and the Stig cyclases

Table S2: Proteomics analysis of FamD2 expression in the TT-assay

Table S3: NMR data characterizing 5-fluoro-12-epi-hapalindole U 15

Table S4: NMR data characterizing 6-fluoro-12-epi-hapalindole U 16

Table S5: NMR data characterizing 5-fluoro-12-epi-fischerindole U 17

Table S6: NMR data characterizing 6-fluoro-12-epi-fischerindole U 18

Table S7: Amino acid sequences of cyclases

\section{Supplemental Figure}

Figure S1 (A-G): Total ion chromatogram (TIC), extracted ion chromatogram (EIC) and comparative MS data of Figure 3 and Figure 4.

Supplemental Figure S2: Total ion chromatogram (TIC) and extracted ion chromatogram (EIC) of Figure 6 (A-C). Figure S3: Spectra of 5-Fluoro-12-epi-hapalindole U 15

Figure S4: Spectra of 6-Fluoro-12-epi-hapalindole U 16

Figure S5: Spectra of 5-Fluoro-12-epi-fischerindole U 17

Figure S6: Spectra of 6-Fluoro-12-epi-fischerindole U 18

\section{Supplemental data sheet}

Excel Sheet 1: Proteomics data for FamD2

Excel Sheet 2: Proteomics data for FamD2 and FamC1

Excel Sheet 3: Proteomics data for FamD2 and FisC 
Supplemental Figure S1: Total ion chromatogram (TIC), extracted ion chromatogram (EIC) and comparative MS data of Figure 3 and Figure 4.

Panel 1: TIC (A) and EIC of hapalindole product $(\mathrm{m} / \mathrm{z}$ 305) (B) and cis-indole isonitrile $2(\mathrm{~m} / \mathrm{z}, 169)$ (C) compared with the standard 2 (D) for the in vitro TT-assay performed in the absence of cyclase and FamD2 plasmids (for Figure 3 A). Panel 2: MS data of the product (top) and the standard 2 (bottom) are shown.

\section{Panel 1}

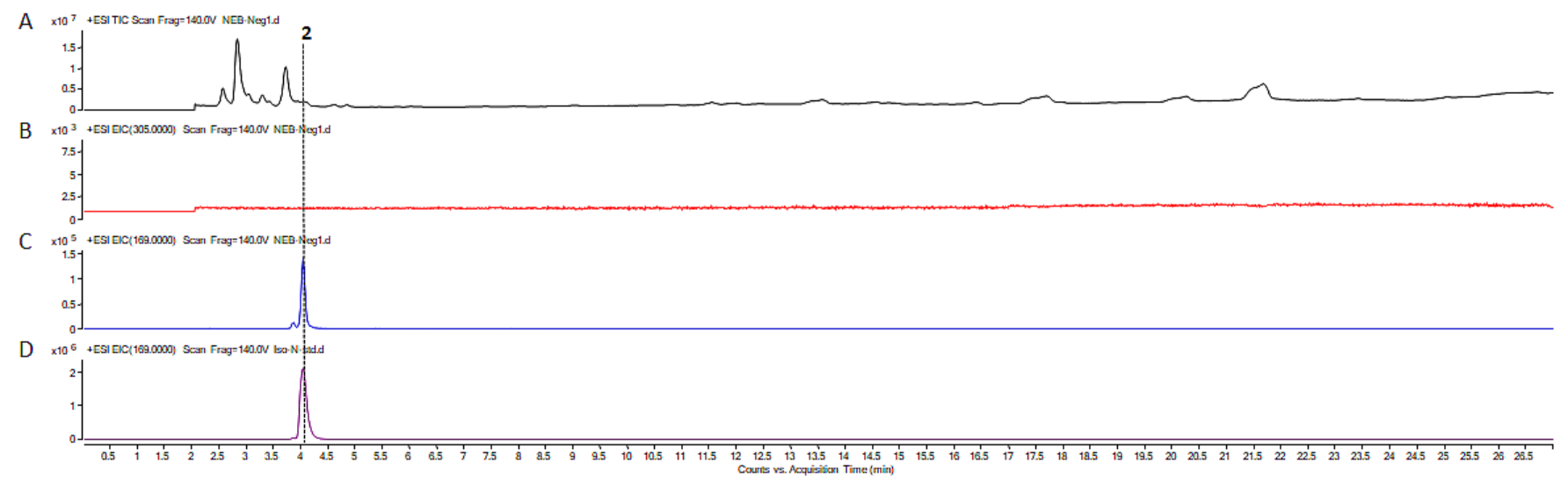

Panel 2

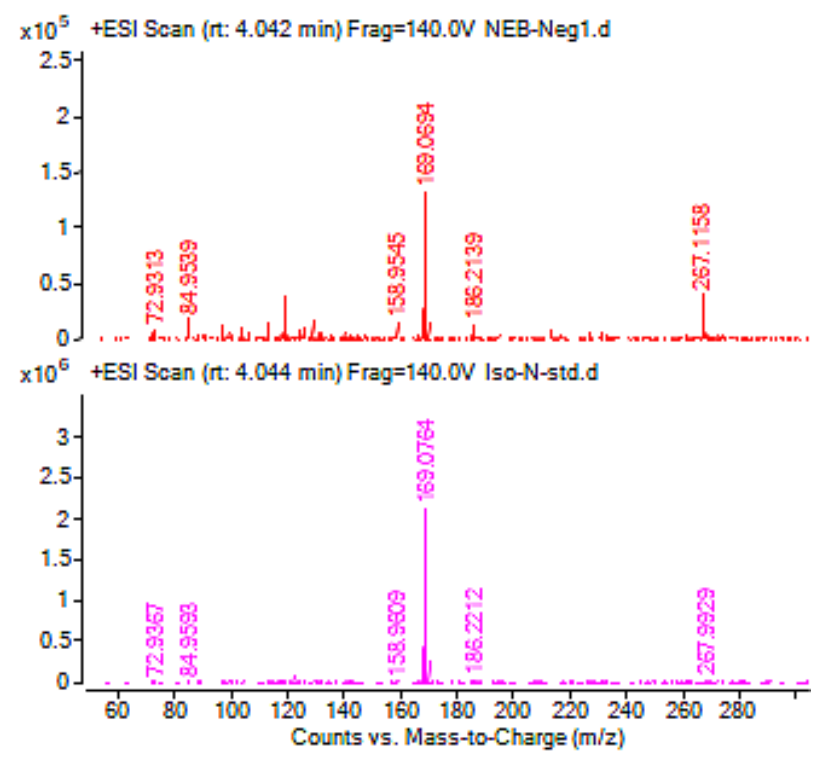


B. Panel 1: TIC (A) and EIC of cis-indole isonitrile $2(\mathrm{~m} / \mathrm{z}, 169)$ (B) and cis-indole isonitrile-GPP intermediate 3 $(\mathrm{m} / \mathrm{z}$ 305) (C) compared with the standard $\mathbf{3}$ (D) for the in vitro TT-assay performed in the presence of FamD2 plasmid alone (for Figure 3 B). Panel 2: MS data of the product (top) and the standard 3 (bottom) are shown.

\section{Panel 1}

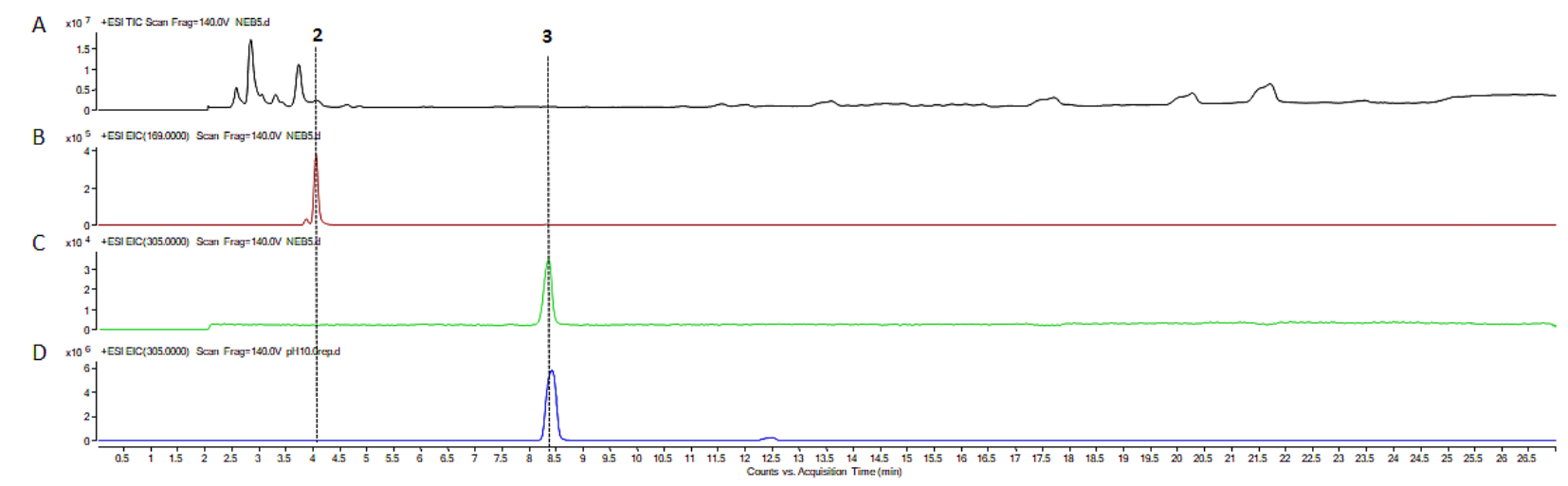

Panel 2

$\times 10^{6}+$ ESIScan (it $\left.8.301 \mathrm{~min}\right)$ Frag=140.0V NEB5.d

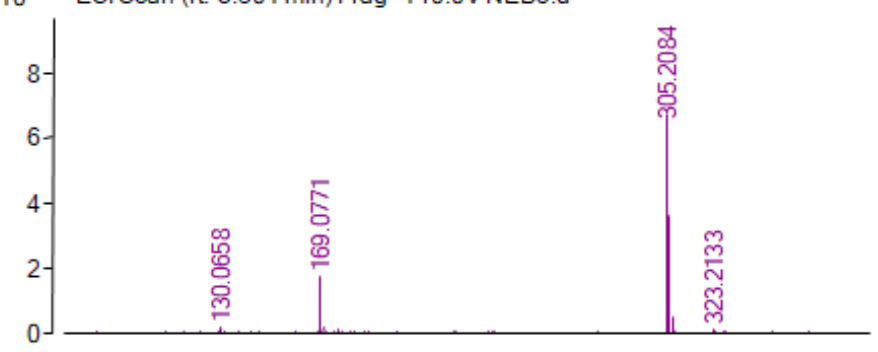

$\times 10^{7}+$ ESIScan (rt: $8.295 \mathrm{~min}$ ) Frag $=140.0 \mathrm{VpH} 10.0 . \mathrm{d}$

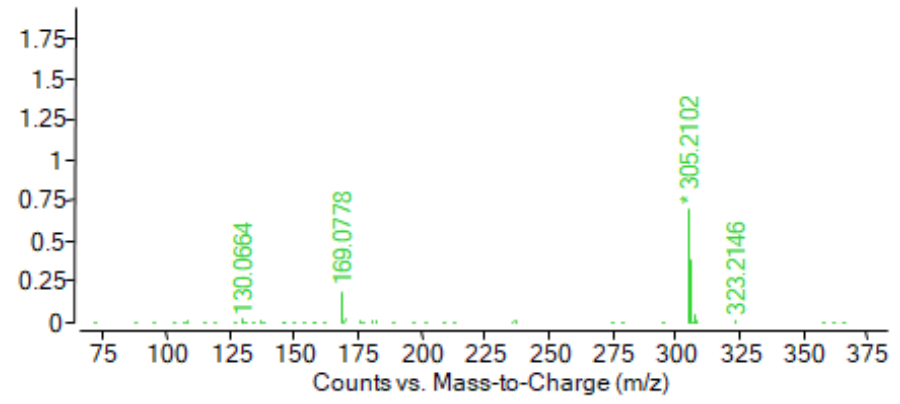


C. Panel 1: TIC (A) and EIC of cis-indole isonitrile $2(\mathrm{~m} / \mathrm{z}$ 169) (B), cis-indole isonitrile-GPP intermediate $3(\mathrm{~m} / \mathrm{z}$ 305) (C) and 12-epi-hapalindole U $4(\mathrm{~m} / \mathrm{z} 305)$ (D) compared with the standard 4 (E) for the in vitro TT-assay performed in the presence of FamD2 and FamC1 plasmids (for Figure $3 \mathrm{C}$ ). Panel 2: MS data of the product (top) and the standard 4 (bottom) are shown.

\section{Panel 1}

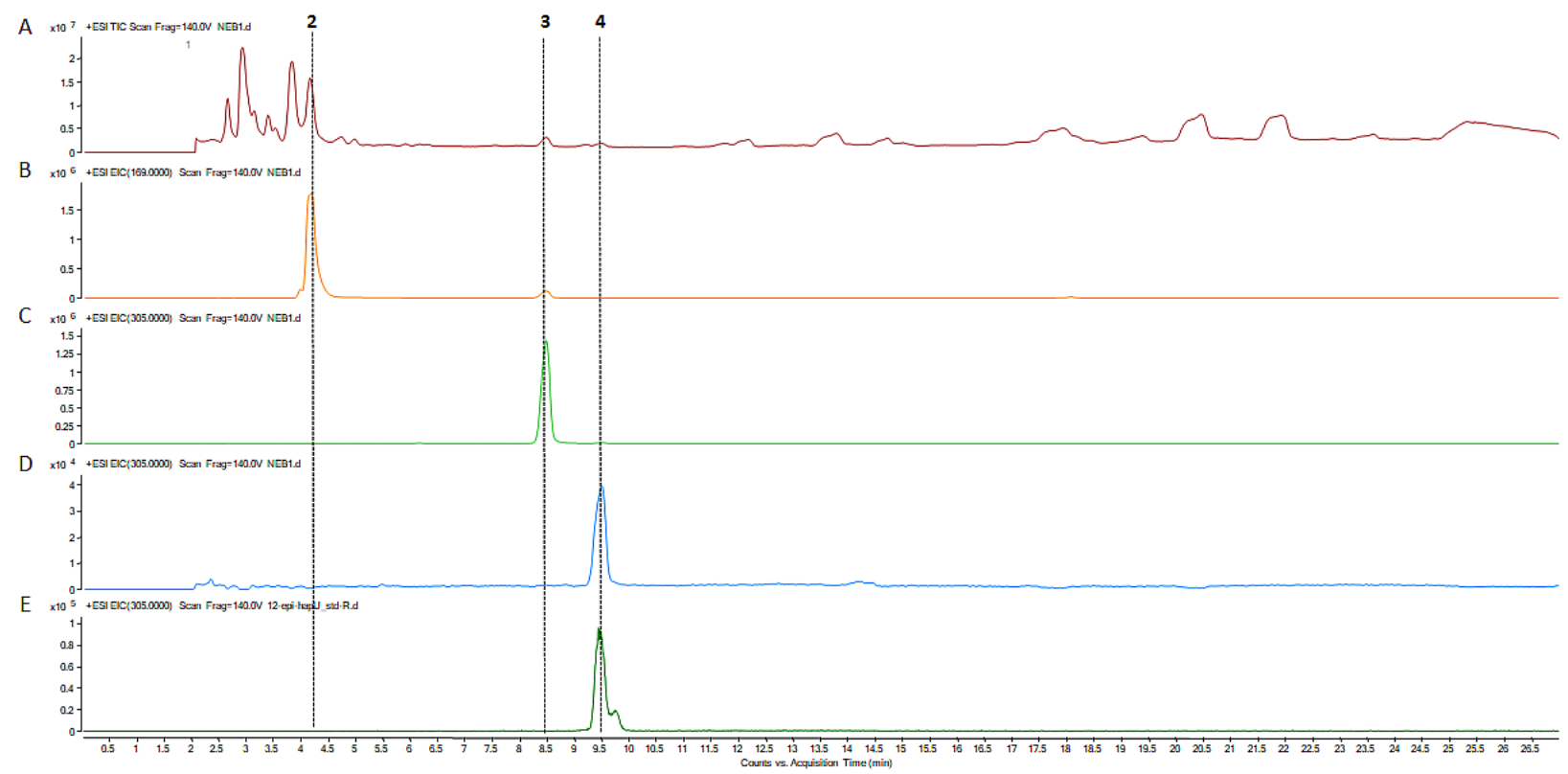

\section{Panel 2}

$x 10^{5}+$ ESIScan (it: $9.568 \mathrm{~min}$ ) Frag=140.0V NEB1.d

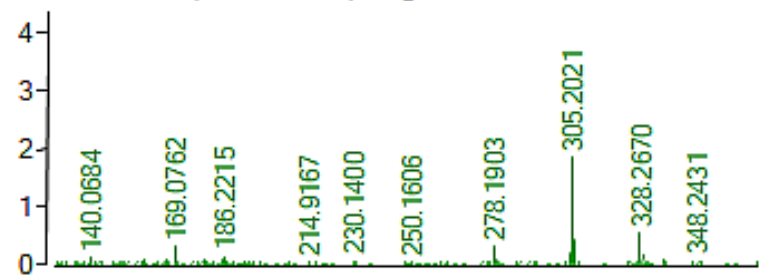

x10 + +ESI Scan (rt: 9.543 min) Frag=140.0V 12-epi-hapU_std-R.d

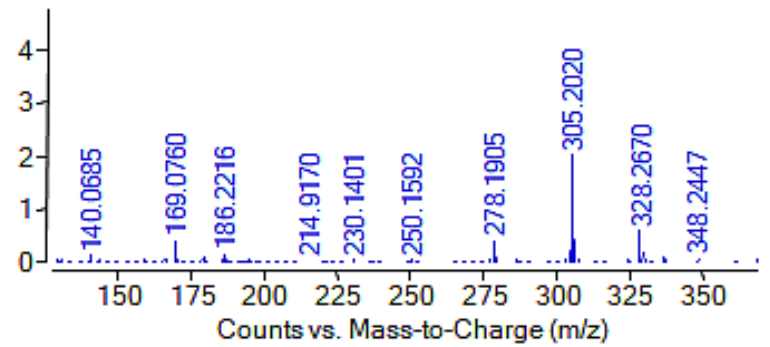


D. Panel 1: TIC (A) and EIC of cis-indole isonitrile $2(\mathrm{~m} / \mathrm{z}$ 169) (B), cis-indole isonitrile-GPP intermediate $3(\mathrm{~m} / \mathrm{z}$ $305)$ and hapalindole $\mathrm{H} 6(\mathrm{~m} / \mathrm{z}, 305)$ product $(\mathrm{C})$ were compared with the standard $\mathbf{6}$ (D) for the in vitro TT-assay performed in the presence of FamD2 and FamC2 plus FamC3 plasmids in the presence of lower $5 \mathrm{mM}$ calcium (for Figure 3E). Panel 2: MS data of the product (top) and the standard 6 (bottom) are shown.

\section{Panel 1}

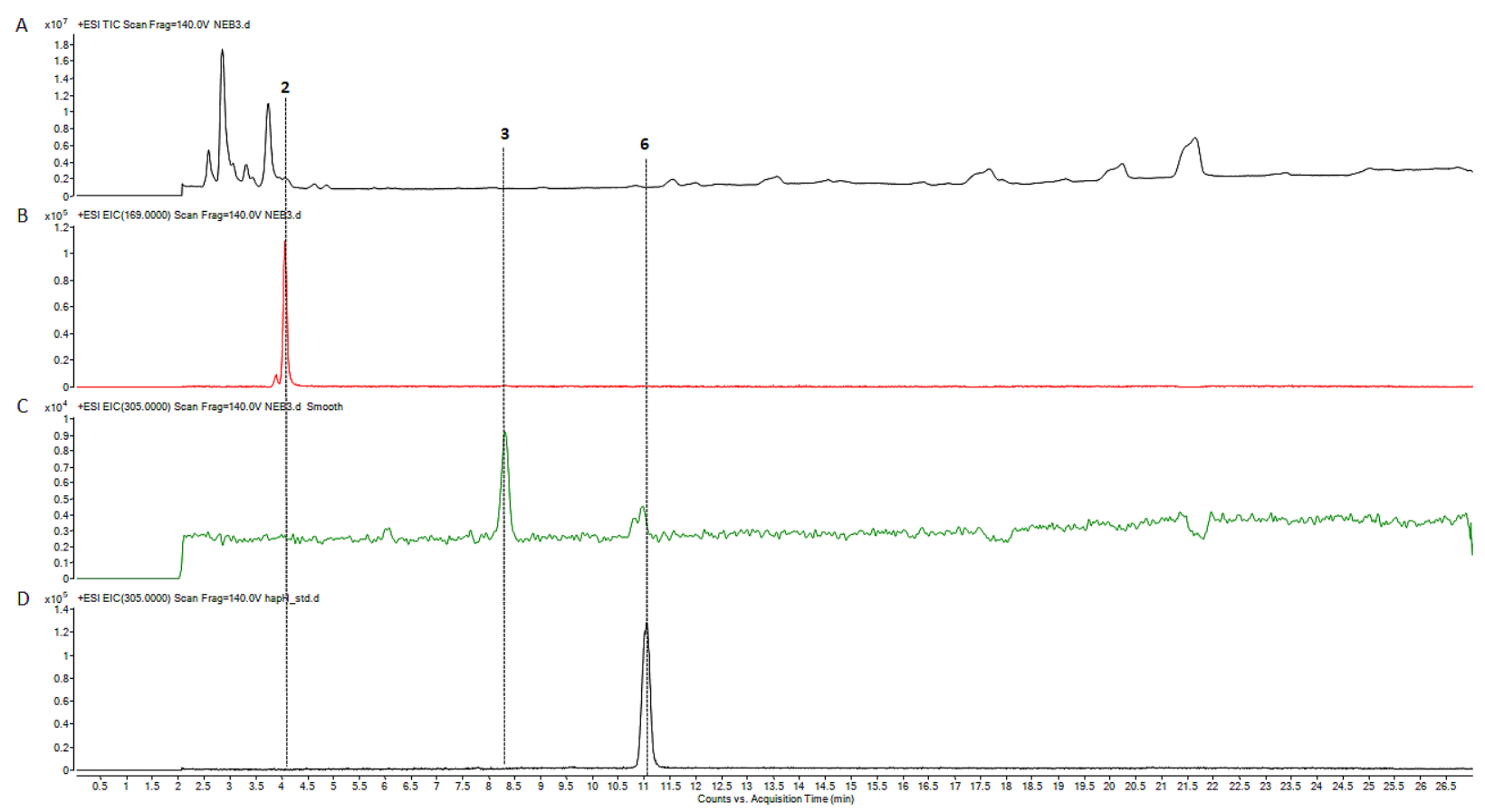

\section{Panel 2}

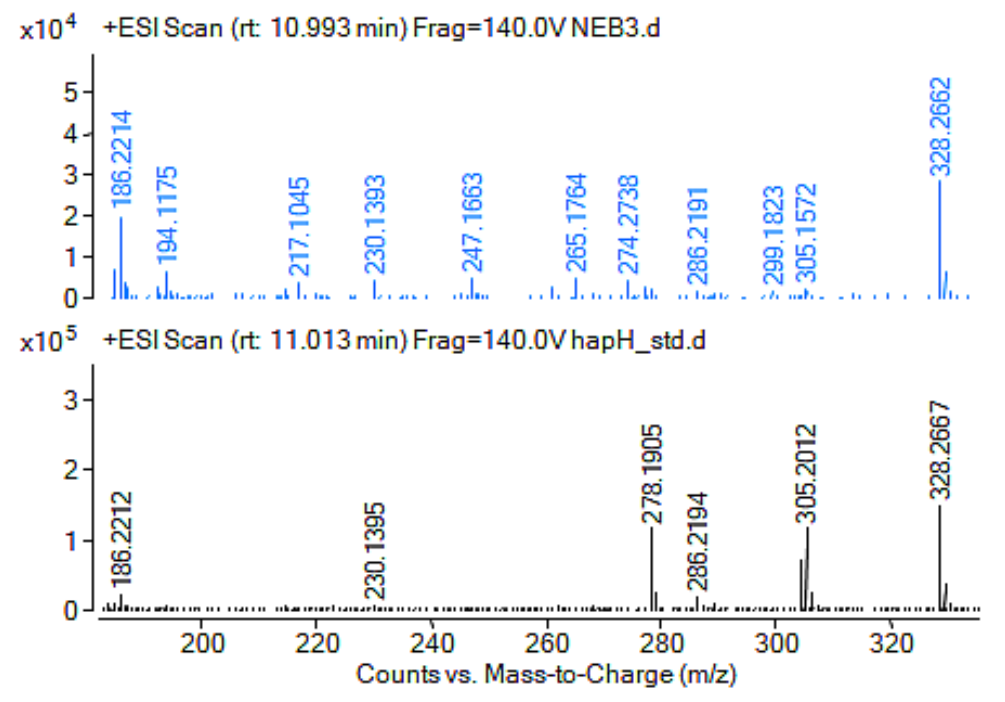


E. Panel 1: TIC (A) and EIC of cis-indole isonitrile $2(\mathrm{~m} / z$ 169) (B), and cis-indole isonitrile-GPP intermediate 3 $(\mathrm{m} / \mathrm{z} 305)$ and hapalindole $\mathrm{H} \mathbf{6}(\mathrm{m} / \mathrm{z}$ 305) (C) compared with the standard $\mathbf{6}$ (D) for the in vitro TT-assay performed in the presence of FamD2 and FamC2 plus FamC3 plasmids in the presence of higher $20 \mathrm{mM}$ calcium (for Figure 3 E). Panel 2: MS data of the product (top) and the standard 6 (bottom) are shown.

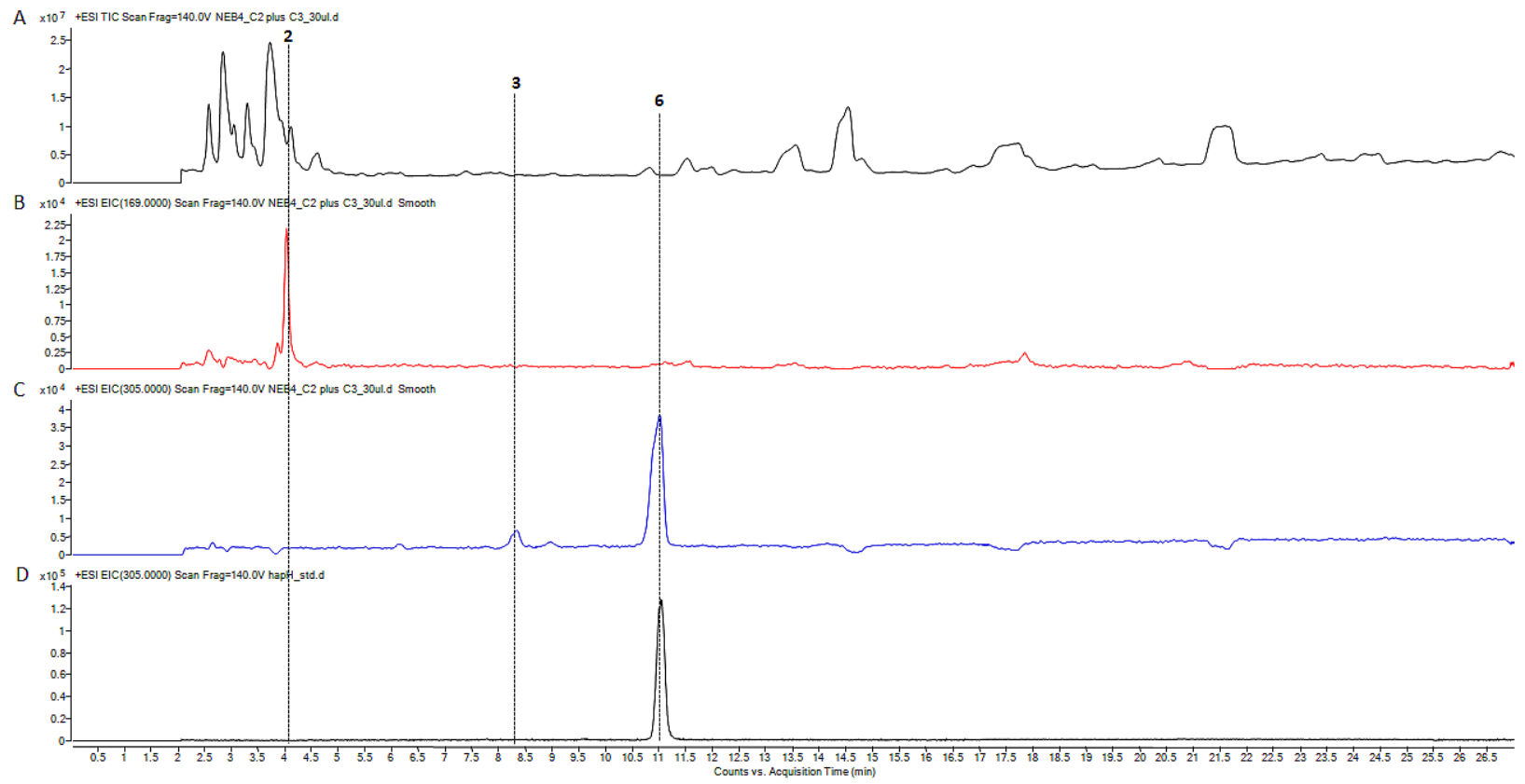

\section{Panel 2}

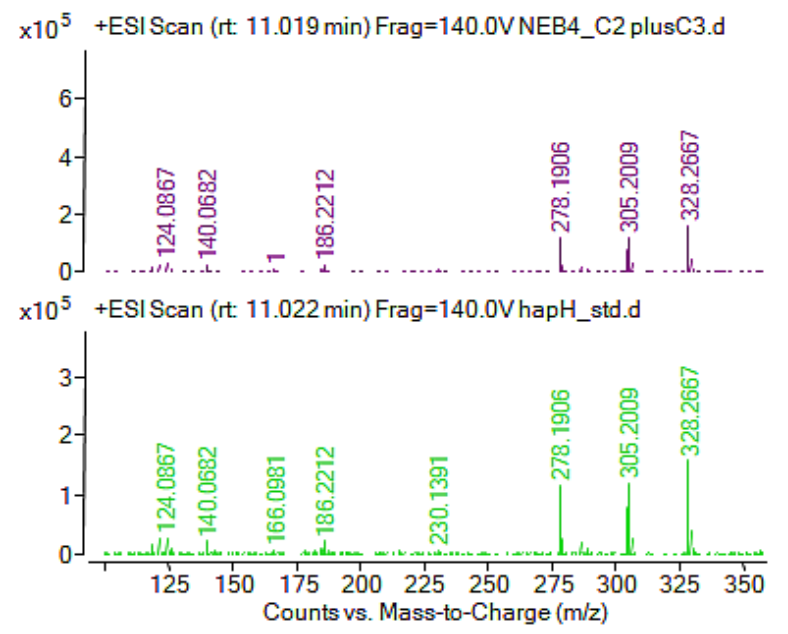


F. Panel 1: TIC (A) and EIC of cis-indole isonitrile $2(\mathrm{~m} / \mathrm{z}, 169)$ (B) and hapalindole U $5(\mathrm{~m} / \mathrm{z}, 305)$ (C) for the in vitro TT-assay performed in the presence of FamD2 and FamC1 plus FamC4 plasmids in the presence of lower 5 $\mathrm{mM}$ calcium concentration. Note that lower concentration of calcium did not show distinct product. Panel 2: TIC (A) and EIC of cis-indole isonitrile 2 ( $\mathrm{m} / \mathrm{z}$ 169) (B), and hapalindole U 5 and 12-epi-hapalindole U $4(\mathrm{~m} / \mathrm{z}$ 305) (C) compared with the standard 5 (D) and 4 (E) for the in vitro TT-assay performed in the presence of FamD2 and FamC2 plus FamC3 plasmids in the presence of higher $20 \mathrm{mM}$ calcium concentration. Panel 3: MS data of the product (top) and the standard $\mathbf{5}$ (bottom) are shown.

\section{Panel 1}

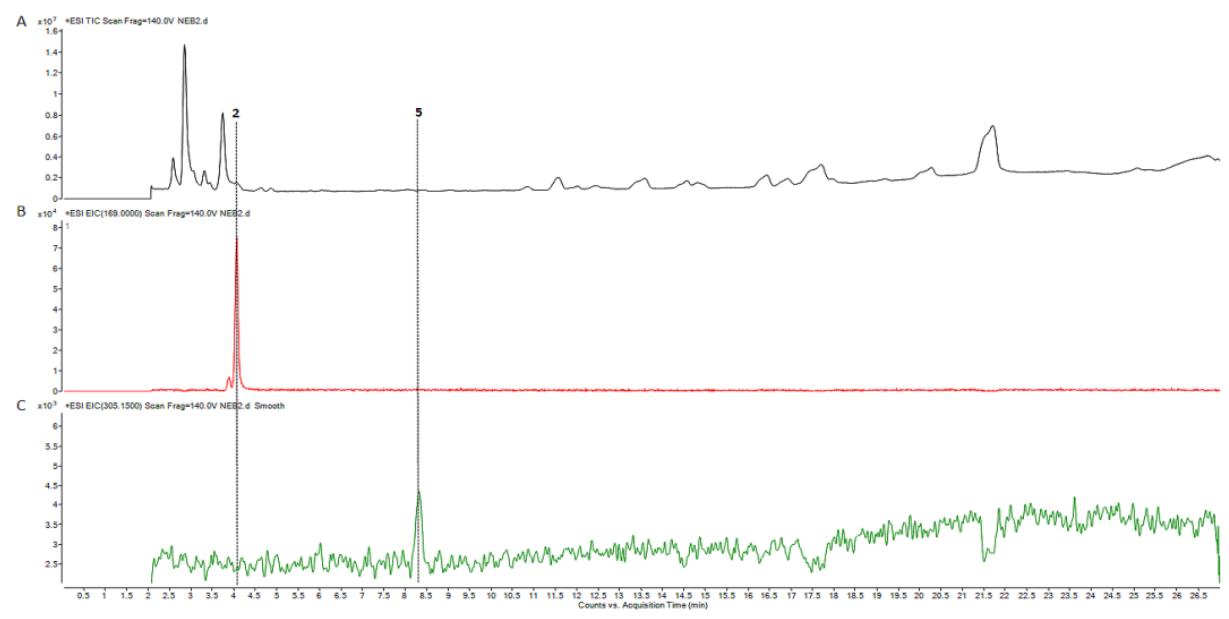

\section{Panel 2}

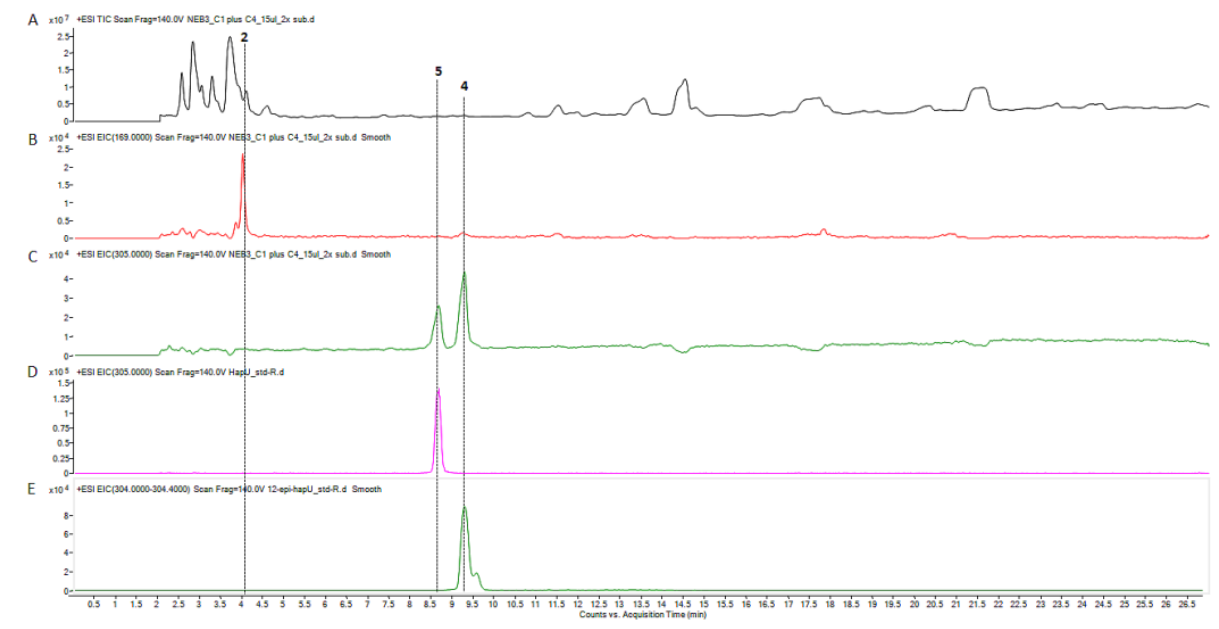

\section{Panel 3}

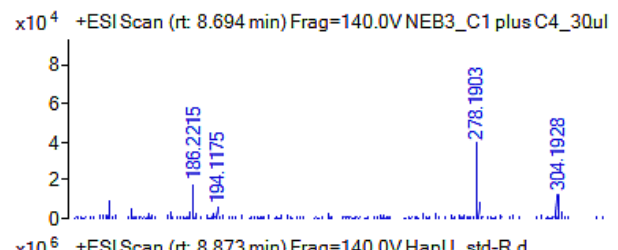

$\mathrm{x} 10^{6}+$ ESIScan (rt: $8.873 \mathrm{~min}$ ) Frag=140.0V HapU_std-R.d

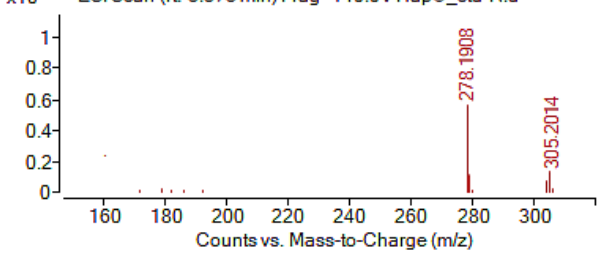


G. Panel 1: TIC (A) and EIC of cis-indole isonitrile $2(\mathrm{~m} / \mathrm{z}$ 169) (B) and 12-epi-fischerindole U $7(\mathrm{~m} / \mathrm{z} 305)$ (C) compared with the standard 7 (D) for the in vitro TT-assay performed in the presence of FamD2 and FisC plasmids (for Figure 4C). Panel 2: MS data of the product (top) and the standard 7 (bottom) are shown.

\section{Panel 1}

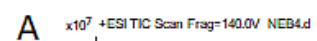

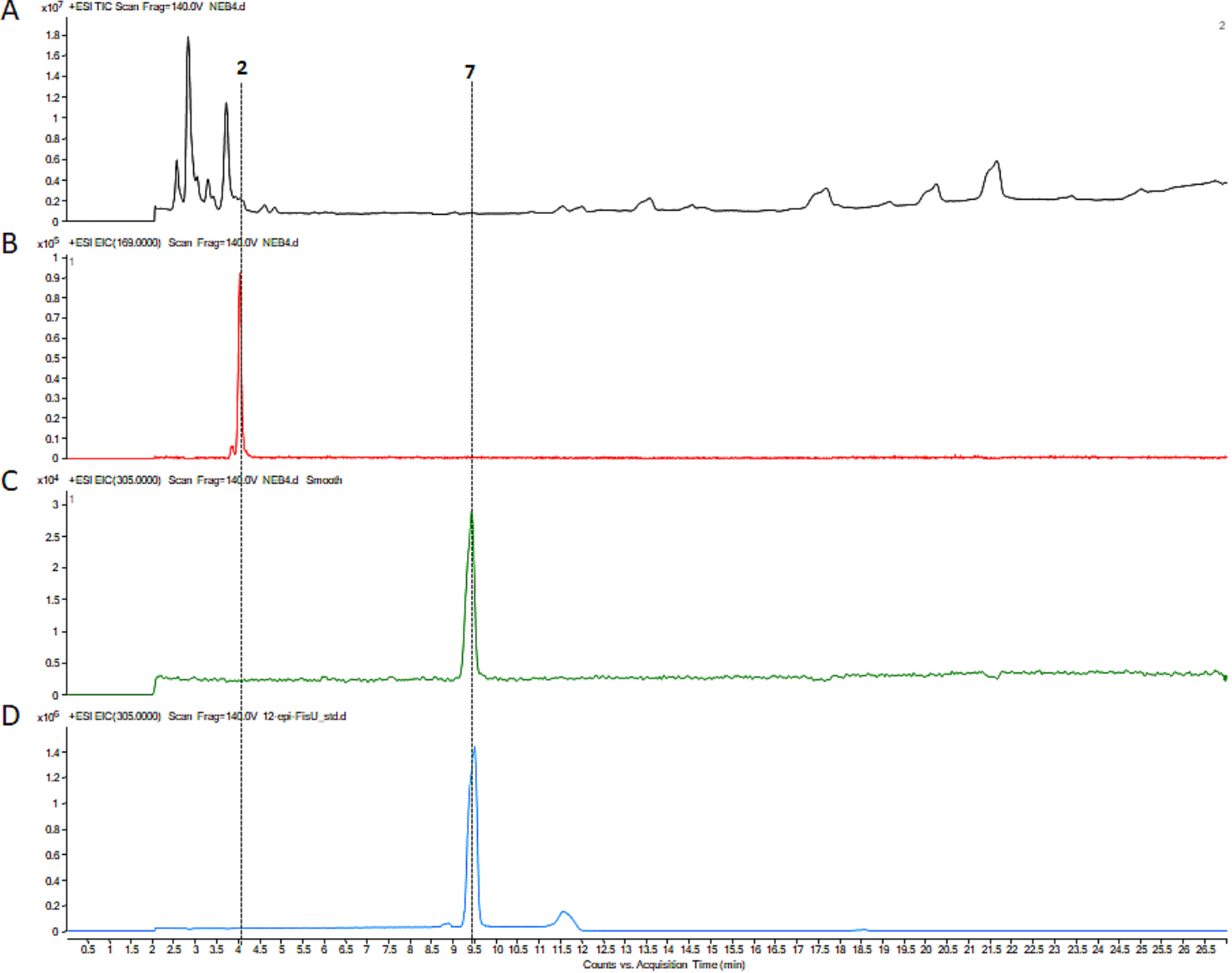

\section{Panel 2}

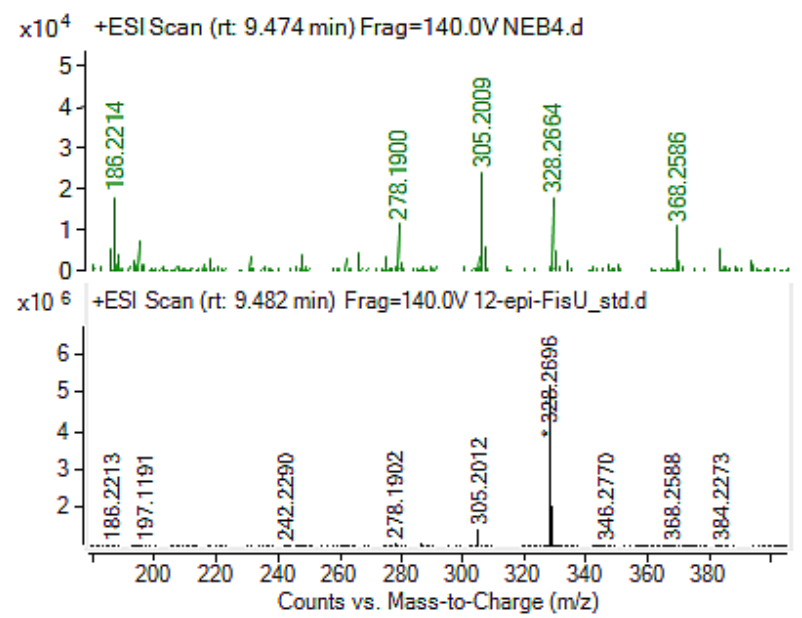


Supplemental Figure S2: Total ion chromatogram (TIC), extracted ion chromatogram (EIC) and comparative MS data of Figure 6 (A-C).

TIC (A) and EIC ( $m / 2$ 187.02) of fluorinated cis-indole isonitrile substrate 9 (Panel 1 and 3 ) and $\mathbf{1 0}$ (Panel 2 and 4), and the fluorinated hapalindole products 15, 16 (Panel 1-2) and fischerindole products 17, 18 (Panel 3-4) were compared with the standard 15, 16, 17 and 18 for the in vitro TT-assay performed in the presence FamD2 with FamC1 (Panel 1-2) or FisC (Panel 3-4) plasmids (for Figure 6). The '*' represents 5F-/6F-12-epi-hapalindole-GPP (Panel 1-2) and 5F-/6F-12-epi-fisherindiole-GPP (Panel 3-4). Panel 1, 2, 3 and 4 represents the Figure 6 A, 6B, 6C and $6 \mathrm{D}$.

\section{Panel 1}

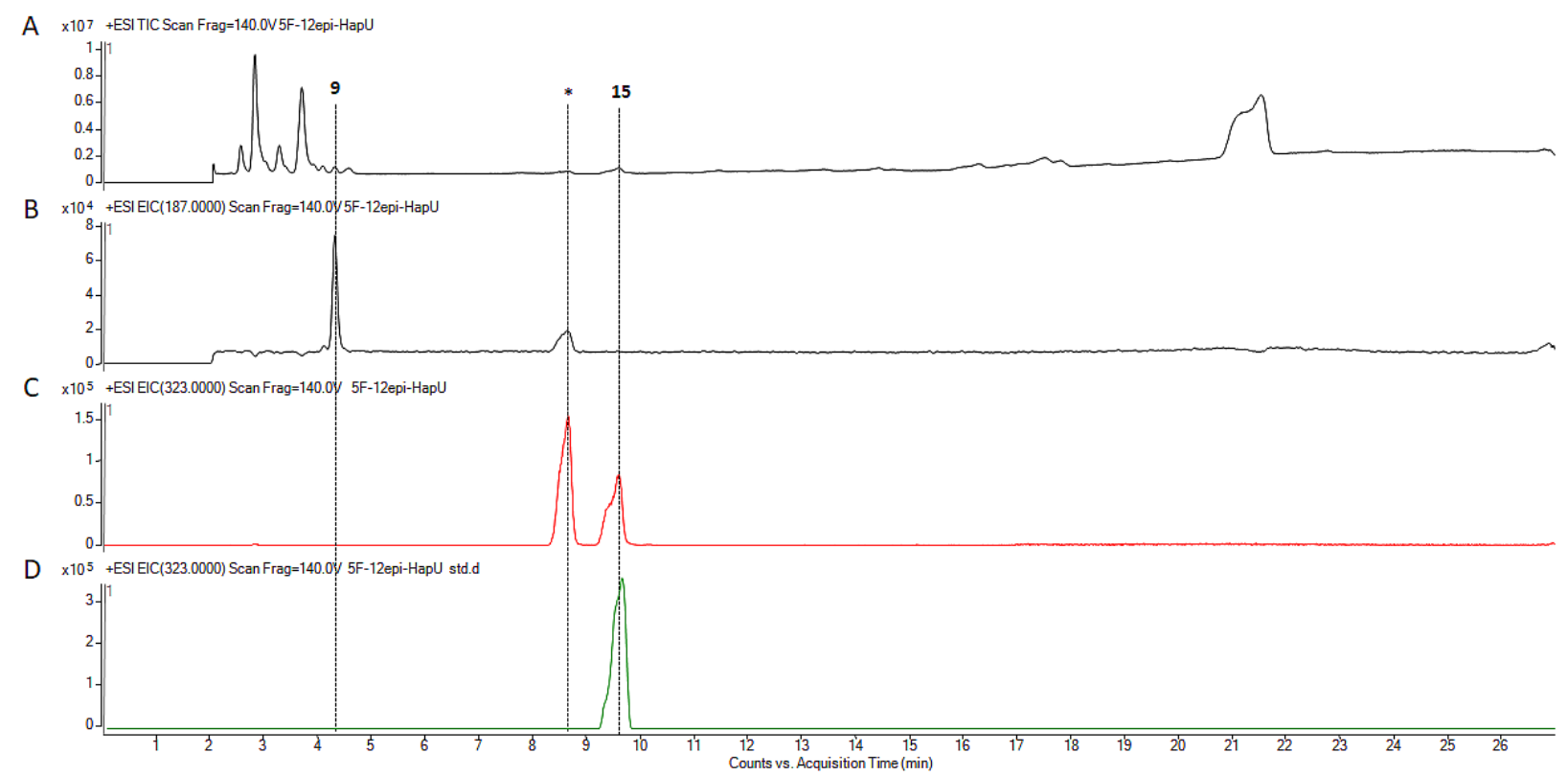

Panel 2

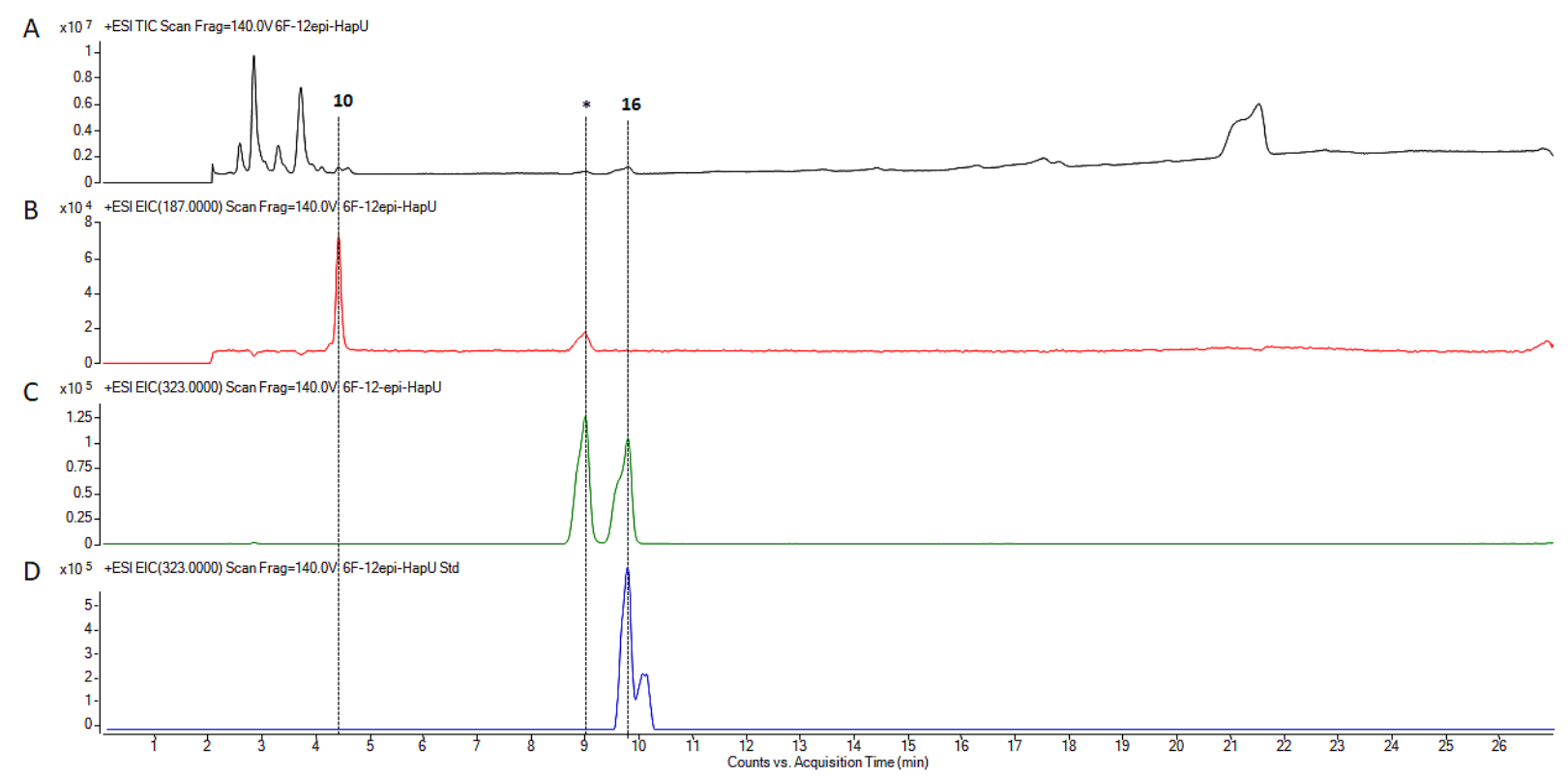




\section{Panel 3}

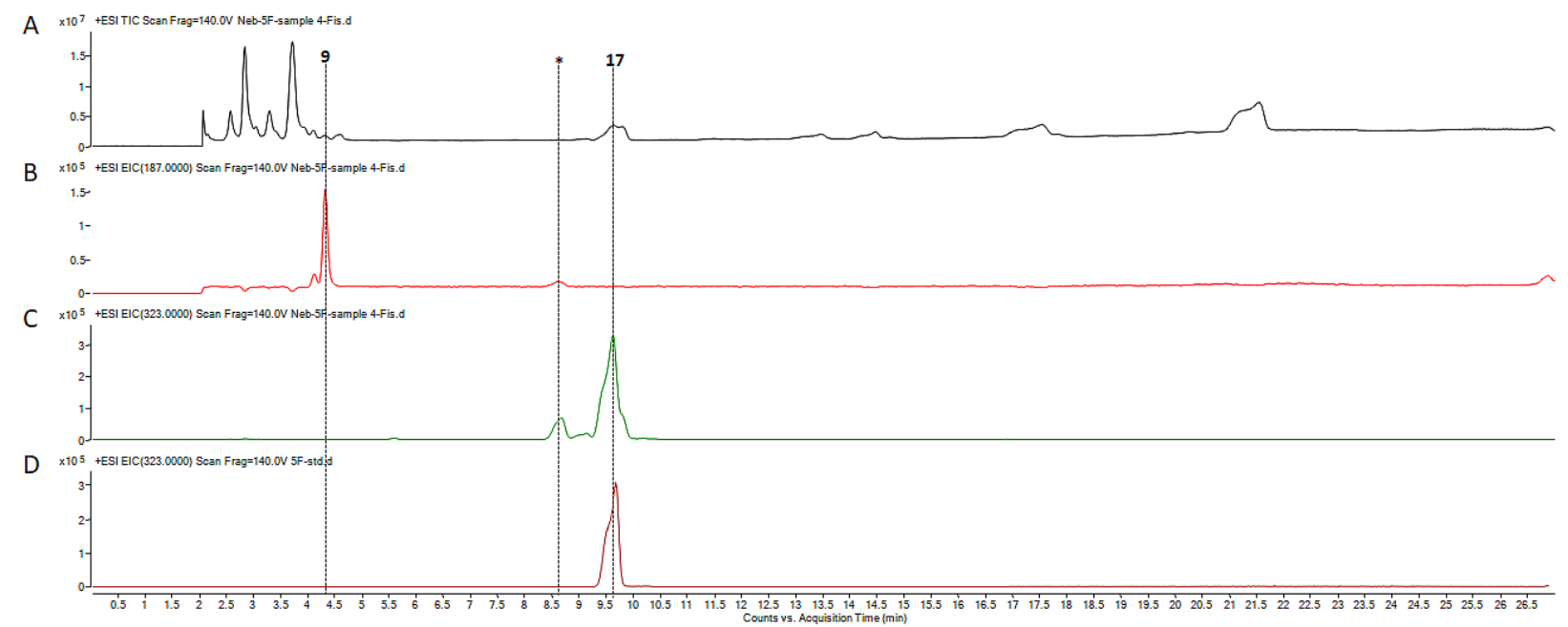

\section{Panel 4}

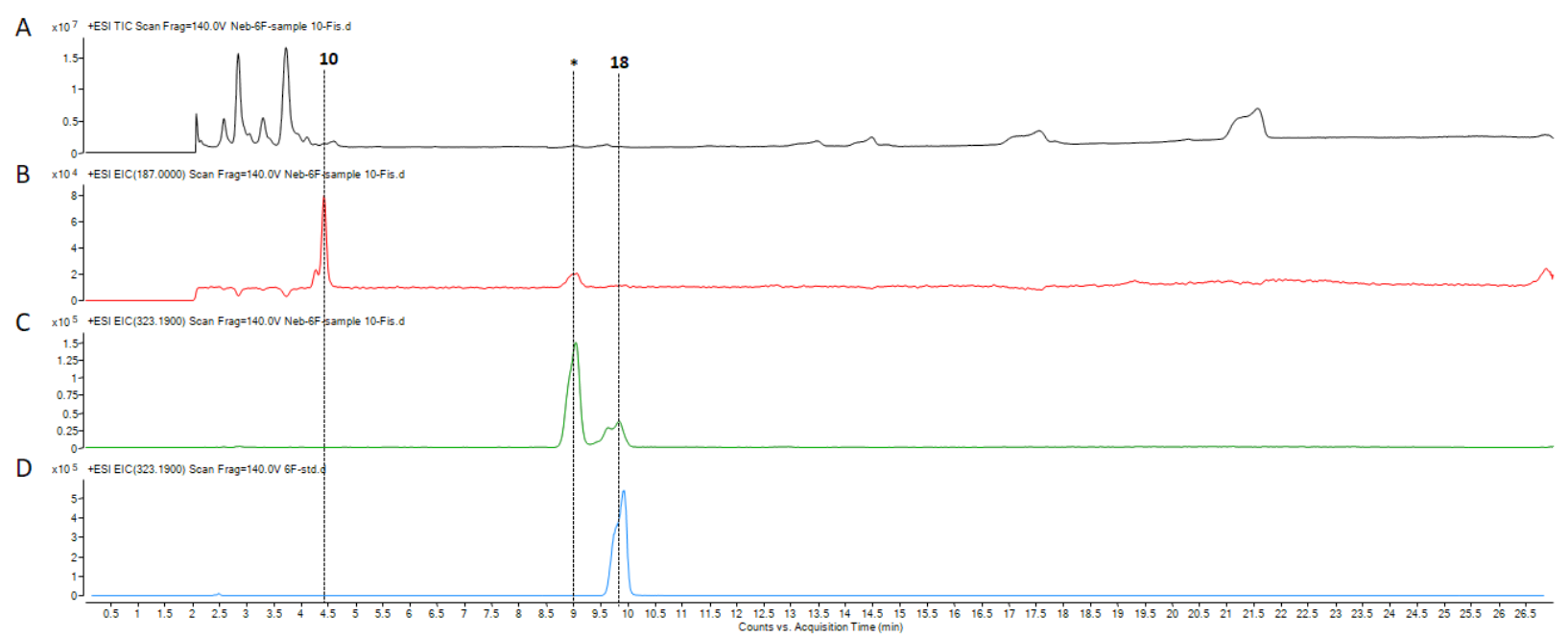




\section{Supplemental Table}

Table S1: Assigned numeral representation for the synthetic substrates, prenyltransferase and the Stig cyclases involved in the biosynthesis of natural and unnatural hapalindole/fischerindole are shown.

\begin{tabular}{|c|c|c|c|}
\hline $\begin{array}{l}\text { Synthesis/ } \\
\text { Designated Protein }\end{array}$ & Substrate & Product & $\begin{array}{l}\text { Assigned } \\
\text { Number }\end{array}$ \\
\hline \multicolumn{4}{|c|}{ Natural hapalindole/fischerindole system } \\
\hline Synthesized & geranyl pyrophosphate (GPP) & & 1 \\
\hline Synthesized & cis-indole isonitrile & & 2 \\
\hline \multicolumn{4}{|l|}{ Enzymes } \\
\hline Prenyltransferase (FamD2) & 1 and 2 & cis-indole isonitrile-GPP (3GC) & 3 \\
\hline \multicolumn{4}{|l|}{ Sig cyclases } \\
\hline FamC1 & 3 & 12-epi-hapalindole $\mathrm{U}$ & 4 \\
\hline FamC1 and FamC4 & 3 & Hapalindole U & 5 \\
\hline FamC3 and FamC4 & 3 & Hapalindole $\mathrm{H}$ & 6 \\
\hline FisC & 3 & 12-epi-fischerindole $\mathrm{U}$ & 7 \\
\hline \multicolumn{4}{|c|}{ Unnatural hapalindole/fischerindole system } \\
\hline Synthesized & 5-fluoro-cis-indole isonitrile & & 9 \\
\hline Synthesized & 6-fluoro-cis-indole isonitrile & & 10 \\
\hline \multicolumn{4}{|l|}{ Enzymes } \\
\hline FamC1 & $\mathbf{1}$ and $\mathbf{9}$ & 5-fluoro-12-epi-hapalindole U & 15 \\
\hline FamC1 & 1 and 10 & 6-fluoro-12-epi-hapalindole U & 16 \\
\hline FisC & 1 and 9 & 5-fluoro-12-epi-fischerindole $\mathrm{U}$ & 17 \\
\hline FisC & $\mathbf{1}$ and $\mathbf{1 0}$ & 6-fluoro-12-epi-fischerindole U & 18 \\
\hline
\end{tabular}


Table S2: Proteomics analysis of FamD2 expression in the TT-assay containing exogenous plasmids FamD2, and the substrates 1 and 2 during cis-indole isonitrile-GPP intermediate 3 synthesis. The sequence highlighted in yellow showed the coverage of the synthesized protein. Note: Please see attached Excel Sheet 1

\begin{tabular}{|c|c|c|}
\hline \multicolumn{3}{|l|}{ FamD2 } \\
\hline Total peptide & 25 & \\
\hline Unique peptide & 25 & \\
\hline Total PSM & 906 & \\
\hline Coverage $(\%)$ & 72.49 & \\
\hline Annotated Peptide Sequence & $\begin{array}{l}\text { Sequence } \\
\text { Positions }\end{array}$ & $\begin{array}{l}\text { PSM } \\
\text { FamD2 }\end{array}$ \\
\hline [-].MNDVNR.[I] & FamD2[1-6] & 1 \\
\hline [R].IRTDIINVAK.[T] & FamD2 [7-16] & 30 \\
\hline [R].TDIINVAK.[T] & FamD2 [9-16] & 11 \\
\hline [K].TFGAEYSEK.[V] & FamD2 [17-25] & 14 \\
\hline [K].VLDEVFQVFGEQFADNSFMIR.[T] & FamD2 [26-46] & 155 \\
\hline [R].TSNKQPDK.[L] & FamD2 [47-54] & 10 \\
\hline [R].TSNKQPDKLGCYFR.[Y] & FamD2 [47-60] & 2 \\
\hline [K].QPDKLGCYFR.[Y] & FamD2 [51-60] & 7 \\
\hline [K].LGCYFR.[Y] & FamD2 [55-60] & 16 \\
\hline [R].YHEEDESQLGLAWDIAR.[K] & FamD2 [61-77] & 335 \\
\hline $\begin{array}{l}\text { [R].KSGLLSDQGRPVDQLIPEICETFPI } \\
\text { MADGVDFDVK.[H] }\end{array}$ & FamD2 [78-112] & 45 \\
\hline $\begin{array}{l}\text { [K].SGLLSDQGRPVDQLIPEICETFPIM } \\
\text { ADGVDFDVK.[H] }\end{array}$ & FamD2 [79-112] & 28 \\
\hline [K].IWQSIK.[G] & FamD2 [118-123] & 12 \\
\hline [K].GVVPVQDAFK.[L] & FamD2 [124-133] & 22 \\
\hline [K].LSLPASVTTHSDFLK.[N] & FamD2 [134-148] & 42 \\
\hline [K].HHTSEYYK.[N] & FamD2 [178-185] & 1 \\
\hline [R].LCFYLPFLNR.[E] & FamD2 [224-233] & 5 \\
\hline [R].EAVPQNLLNPLLK.[K] & FamD2 [234-246] & 42 \\
\hline [R].EAVPQNLLNPLLKK.[Y] & FamD2 [234-247] & 14 \\
\hline $\begin{array}{l}\text { [K].KYINEAPALVDNPGFILGWSFGPQ } \\
\text { GGK.[G] }\end{array}$ & FamD2 [247-273] & 10 \\
\hline $\begin{array}{l}\text { [K].YINEAPALVDNPGFILGWSFGPQG } \\
\text { GK.[G] }\end{array}$ & FamD2 [248-273] & 16 \\
\hline [K].VDVDYHGR.[T] & FamD2 [279-286] & 3 \\
\hline [R].TVPLFMK.[V] & FamD2 [287-293] & 64 \\
\hline [R].TVPLFMKVHSQPLPK.[A] & FamD2 [287-301] & 1 \\
\hline [K].VHSQPLPK.[A] & FamD2 [294-301] & 6 \\
\hline \multicolumn{3}{|c|}{$\begin{array}{l}\text { FamD2 } \\
\text { MNDVNRIRTDIINVAKTFGAEYSEKVLDEVFQVFGEQFADNSFMIRTSN } \\
\text { KQPDKLGCYFRYHEEDESQLGLAWDIARKSGLLSDQGRPVDQLIPEICE } \\
\text { TFPIMADGVDFDVKHGLAKIWQSIKGVVPVQDAFKLSLPASVTTHSDF } \\
\text { LKNHHLDALYAFGIDYHHSSVNLYFDTYHPKHTSEYYKNLLQDLQF } \\
\text { QPPSDELLELLTNNGEIALTFNFASPRIERLCFYLPFLNREAVPQNLLNPL } \\
\text { LKKYINEAPALVDNPGFILGWSFGPQGGKGTYTKVDVDYHGRTVPLF } \\
\text { MKVHSQPLPKAADFALAQ, } 309 \text { residues }\end{array}$} \\
\hline
\end{tabular}


Table S3: NMR characterization of 5-fluoro-12-epi-hapalindole U (15) $[\alpha]_{D^{25}}^{25}+7.7\left(\mathrm{c}=0.07, \mathrm{CH}_{2} \mathrm{Cl}_{2}\right)$

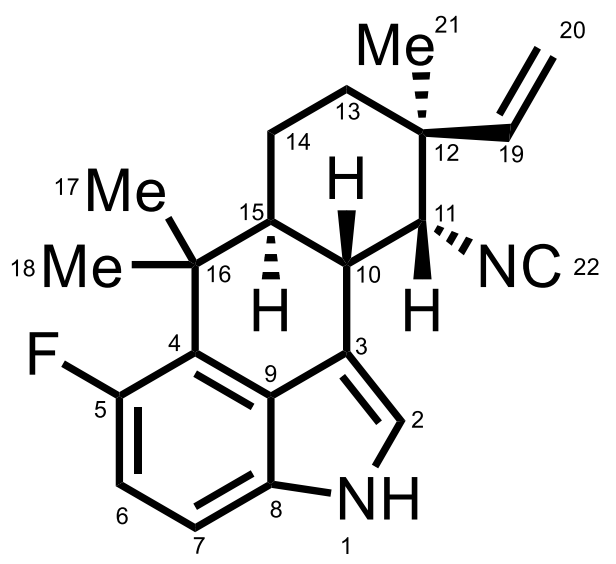

\begin{tabular}{|c|c|c|c|c|}
\hline Position & $\begin{array}{l}{ }^{13} \mathrm{C} \text { shift (ppm) } \\
\text { (Fluorine } \\
\text { coupling) } \mathrm{C}_{6} \mathrm{D}_{6}\end{array}$ & $\begin{array}{l}{ }^{1} \mathrm{H} \text { shift (ppm), } \\
\text { multi (J) } \mathrm{C}_{6} \mathrm{D}_{6}\end{array}$ & $\cos Y$ & HMBC \\
\hline 1 & & 6.55, bs & 2 & \\
\hline 2 & 118.03 & $6.35, \mathrm{~s}$ & 1 & $3,4,8,9$ \\
\hline 3 & 113.75 & & & \\
\hline 4 & $124.13, d,(13.1)$ & & & \\
\hline 5 & $154.29, \mathrm{~d},(236.7)$ & & & \\
\hline 6 & $112.75, d,(29.2)$ & $\begin{array}{l}7.01, \mathrm{dd},(12.9, \\
4.4)\end{array}$ & 6 & $4,5,8$ \\
\hline 7 & $109.71, d,(10.1)$ & $6.69, \mathrm{dd},(3.0,8.7)$ & 7 & $4,5,9$ \\
\hline 8 & 130.96 & & & \\
\hline 9 & $127.08, d,(8.6)$ & & & \\
\hline 10 & 34.58 & $2.90, d,(11.5)$ & 15 & \\
\hline 11 & 63.35 & $3.90, \mathrm{~s}$ & 10 & $10,12,13,15$ \\
\hline 12 & 39.73 & & & \\
\hline 13 & 31.27 & $\begin{array}{l}\text { 1.66, } d,(3.7) \& \\
1.44, m\end{array}$ & 14 & $12,14,15,21$ \\
\hline 14 & 21.17 & $\begin{array}{l}1.48, d,(3.7) \& \\
1.27, m\end{array}$ & 13,15 & $13,15,21$ \\
\hline 15 & 43.98 & $\begin{array}{l}\text { 1.98, td, (12.0, } \\
\text { 3.4) }\end{array}$ & 10,14 & \begin{tabular}{|l|}
$10,11,13,14,16,17,18$ \\
\end{tabular} \\
\hline 16 & 37.27 & & & \\
\hline 17 & 23.07 & $1.11, \mathrm{~s}$ & 18 & $9,15,16,18$ \\
\hline 18 & 25.05 & $1.63, \mathrm{~s}$ & 17 & $9,15,16,17$ \\
\hline 19 & 142.17 & $\begin{array}{l}\text { 5.39, dd, (17.7, } \\
11.0)\end{array}$ & 20 & $11,12,13,21$ \\
\hline 20 & 114.47 & $\begin{array}{l}\text { (cis) 4.91, d, } \\
(11.0) \\
\text { (trans), 4.84, d, } \\
(17.7)\end{array}$ & 19 & $12,19,21$ \\
\hline 21 & 28.35 & $1.18, \mathrm{~s}$ & & $11,12,13,19$ \\
\hline 22 & 160.84 & & & \\
\hline
\end{tabular}


Table S4: NMR characterization of 6-fluoro-12-epi-hapalindole U (16)

$[\alpha]^{25}=+12.9\left(\mathrm{c}=0.04, \mathrm{CH}_{2} \mathrm{Cl}_{2}\right)$

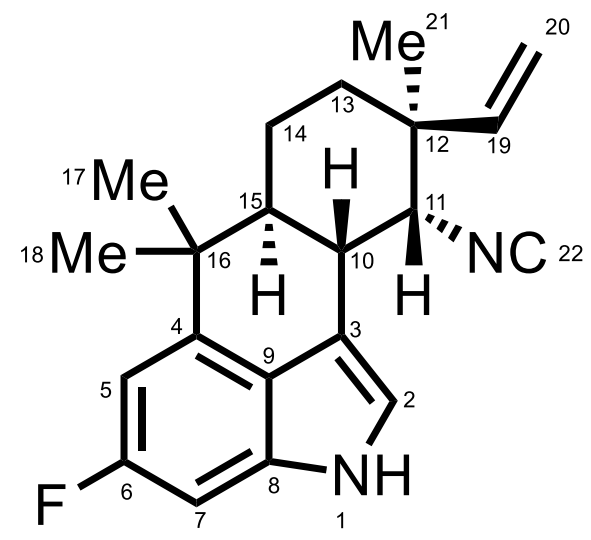

\begin{tabular}{|c|c|c|c|c|}
\hline Position & $\begin{array}{l}{ }^{13} \mathrm{C} \text { shift (ppm) } \\
\text { (Fluorine } \\
\text { coupling) } C_{6} D_{6}\end{array}$ & $\begin{array}{l}{ }^{1} \mathrm{H} \text { shift (ppm), } \\
\text { multi (J) } C_{6} D_{6}\end{array}$ & COSY & HMBC \\
\hline 1 & & 6.51, bs & & \\
\hline 2 & $116.62, d,(3.2)$ & $6.29, \mathrm{~s}$ & & $3,8,9$ \\
\hline 3 & 113.12 & & & \\
\hline 4 & $142.37, \mathrm{~d},(8.7)$ & & & \\
\hline 5 & $102.96, d,(25.9)$ & $\begin{array}{l}\text { 6.93, dd, (11.0, } \\
1.8)\end{array}$ & & $6,7,9$ \\
\hline 6 & $162.10, d,(236.5)$ & & & \\
\hline 7 & $95.36, d,(27.4)$ & $6.69, d,(9.8)$ & & $5,6,9$ \\
\hline 8 & 134.02 & & & \\
\hline 9 & 122.36 & & & \\
\hline 10 & 34.88 & $2.95, d,(11.5)$ & 15 & 3,15 \\
\hline 11 & 63.45 & $3.88, \mathrm{~s}$ & 10 & $10,12,13,15$ \\
\hline 12 & 39.81 & & & \\
\hline 13 & 31.08 & $1.66, \mathrm{~m} \& 1.43, \mathrm{~m}$ & 14 & 11,15 \\
\hline 14 & 21.66 & $\begin{array}{l}1.41, \mathrm{~d},(3.7) \& \\
1.26, \mathrm{~m}\end{array}$ & 13,15 & 19 \\
\hline 15 & 43.57 & $1.93, \mathrm{td},(11.9,3.5)$ & 10,14 & \\
\hline 16 & 37.44 & & & \\
\hline 17 & 24.26 & $1.14, \mathrm{~s}$ & 18 & $4,15,16,18$ \\
\hline 18 & 24.96 & $0.89, \mathrm{~s}$ & 17 & $4,15,16,17,19$ \\
\hline 19 & 142.55 & $\begin{array}{l}5.40, \mathrm{dd},(17.7, \\
11.0)\end{array}$ & 20 & $11,12,13$ \\
\hline 20 & 114.49 & $\begin{array}{l}\text { (cis) 4.92, d, (11.0) } \\
\text { (trans), 4.85, d, } \\
(17.7)\end{array}$ & 19 & 12,19 \\
\hline 21 & 28.27 & $1.17, \mathrm{~s}$ & & $11,12,13,19$ \\
\hline 22 & 160.88 & & & \\
\hline
\end{tabular}


Table S5: NMR characterization of 5-fluoro-12-epi-fischerindole U (17) $[\alpha]_{D^{25}}^{25}=+12.0\left(\mathrm{c}=0.15, \mathrm{CH}_{2} \mathrm{Cl}_{2}\right)$

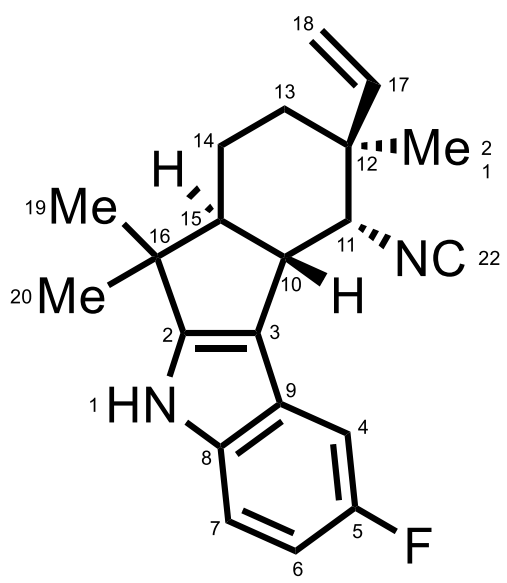

\begin{tabular}{|c|c|c|c|c|}
\hline Position & $\begin{array}{l}{ }^{13} \mathrm{C} \text { shift (ppm) } \\
\text { (Fluorine } \\
\text { coupling) } \mathrm{C}_{6} \mathrm{D}_{6}\end{array}$ & $\begin{array}{l}{ }^{1} \mathrm{H} \text { shift (ppm), } \\
\text { multi (J) } C_{6} D_{6}\end{array}$ & COSY & HMBC \\
\hline 1 & & $6.43, \mathrm{bs}$ & & $2,3,8,9$ \\
\hline 2 & 153.90 & & & \\
\hline 3 & 115.16 & & & \\
\hline 4 & $103.93, d,(23.1)$ & $7.27, \mathrm{dd}(9.4,2.5)$ & 6 & $3,5,6,8$ \\
\hline 5 & $159.42, d,(233.5)$ & & & \\
\hline 6 & $109.07, d,(26.3)$ & $6.99, \mathrm{td},(9.0,2.6)$ & 7 & $4,5,8$ \\
\hline 7 & $112.55, \mathrm{~d},(10.1)$ & $6.81, \mathrm{dd},(8.8,4.4)$ & 6 & $4,5,9$ \\
\hline 8 & 136.53 & & & \\
\hline 9 & $124.63, \mathrm{~d},(10.1)$ & & & \\
\hline 10 & 42.37 & $2.88, \mathrm{~m}$ & 11,15 & $3,9,14,15$ \\
\hline 11 & 62.21 & $3.95, \mathrm{~d}(3.0)$ & 11 & $3,12,13,15,17,22$ \\
\hline 12 & 41.04 & & & \\
\hline 13 & 31.82 & $1.55, \mathrm{~m}$ & 14 & $11,12,14,15,17$ \\
\hline 14 & 20.81 & $\begin{array}{l}1.34, \text { ddd }(13.1, \\
6.8,4.0) \& 1.23, \mathrm{~m}\end{array}$ & 13,15 & $12,13,15$ \\
\hline 15 & 55.21 & $\begin{array}{l}2.36, \text { ddd }(13.3, \\
10.6,3.3)\end{array}$ & 10,14 & $10,14,16,19$ \\
\hline 16 & 40.18 & & & \\
\hline 17 & 143.02 & $\begin{array}{l}\text { 5.31, dd (17.6, } \\
11.0)\end{array}$ & 18 & $11,13,12,21$ \\
\hline 18 & 114.16 & $\begin{array}{l}\text { (cis) 4.87, d (11.1) } \\
\text { (trans) 4.84, d } \\
(17.7)\end{array}$ & 17 & $12,17,21$ \\
\hline 19 & 24.93 & $1.01, \mathrm{~s}$ & & $2,15,16,20$ \\
\hline 20 & 20.78 & $0.74, \mathrm{~s}$ & & $2,15,16,19$ \\
\hline 21 & 28.15 & $1.13, \mathrm{~s}$ & & $11,1213,17$ \\
\hline 22 & 161.39 & & & \\
\hline
\end{tabular}


Table S6: NMR characterization 6-Fluoro-12-epi-Fischerindole U (18) $[\alpha]^{25}=+10.8\left(\mathrm{C}=0.16, \mathrm{CH}_{2} \mathrm{Cl}_{2}\right)$

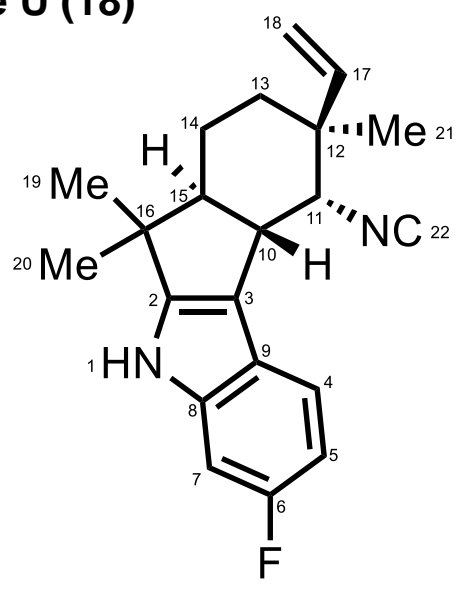

\begin{tabular}{|c|c|c|c|c|}
\hline Position & $\begin{array}{l}{ }^{13} \mathrm{C} \text { shift (ppm), } \\
\text { (Fluorine } \\
\text { coupling) } \mathrm{C}_{6} \mathrm{D}_{6}\end{array}$ & $\begin{array}{l}{ }^{1} \mathrm{H} \text { shift (ppm), } \\
\text { multi (J) } C_{6} D_{6}\end{array}$ & COSY & HMBC \\
\hline 1 & & 6.38, bs & & \\
\hline 2 & $152.16, \mathrm{~d},(3.5)$ & & & \\
\hline 3 & 114.88 & & & \\
\hline 4 & $119.18, d,(10.1)$ & $7.20, \mathrm{dd},(8.6,5.3)$ & 5 & $3,8,9$ \\
\hline 5 & $108.67, d,(24.2)$ & $6.99, \mathrm{td},(9.1,2.4)$ & 4 & $6,7,9$ \\
\hline 6 & $159.78, d,(235.6)$ & & & \\
\hline 7 & $98.80, d,(25.9)$ & $6.85, \mathrm{dd},(9.8,2.3)$ & & $5,6,8,9$ \\
\hline 8 & $139.95, d,(12.0)$ & & & \\
\hline 9 & 121.08 & & & \\
\hline 10 & 42.51 & $2.89, \mathrm{~m}$ & 11,15 & 15 \\
\hline 11 & 62.44 & $4.03, \mathrm{~s}$ & 10 & $10,12,13,15,22$ \\
\hline 12 & 41.03 & & & \\
\hline 13 & 31.87 & $1.56, \mathrm{~m}$ & 14 & $11,12,14,15,21$ \\
\hline 14 & 20.82 & $1.35, \mathrm{~m} \& 1.24, \mathrm{~m}$ & 13 & $10,13,15$ \\
\hline 15 & 55.21 & $\begin{array}{l}\text { 2.36, ddd, (13.4, } \\
10.6,3.2)\end{array}$ & 10,14 & 14,19 \\
\hline 16 & 40.25 & & & \\
\hline 17 & 143.08 & $\begin{array}{l}\text { 5.34, dd, (17.5, } \\
11.0)\end{array}$ & 18 & $11,12,13$ \\
\hline 18 & 114.16 & $\begin{array}{l}\text { Cis } 4.89, d,(11.0) \\
\text { Trans 4.87, d, } \\
(17.5)\end{array}$ & 17 & 12,17 \\
\hline 19 & 25.07 & $1.02, \mathrm{~s}$ & 20 & $2,15,16,20$ \\
\hline 20 & 20.70 & $0.74, \mathrm{~s}$ & 19 & $2,15,16,19$ \\
\hline 21 & 28.17 & $1.15, \mathrm{~s}$ & & $11,12,13,17$ \\
\hline 22 & 161.26 & & & \\
\hline
\end{tabular}


Figure S3: Spectra of 5-fluoro-12-epi-hapalindole U (15)

${ }^{1} \mathrm{H},{ }^{13} \mathrm{C}$, COSY, HSQC, HMBC NMR spectra and HRMS of 5-F-12-epi-Hapalindole $U 15$ in $\mathrm{C}_{6} \mathrm{D}_{6}$ at 600 $\mathrm{MHZ}$ and $125 \mathrm{MHz}$ respectively.

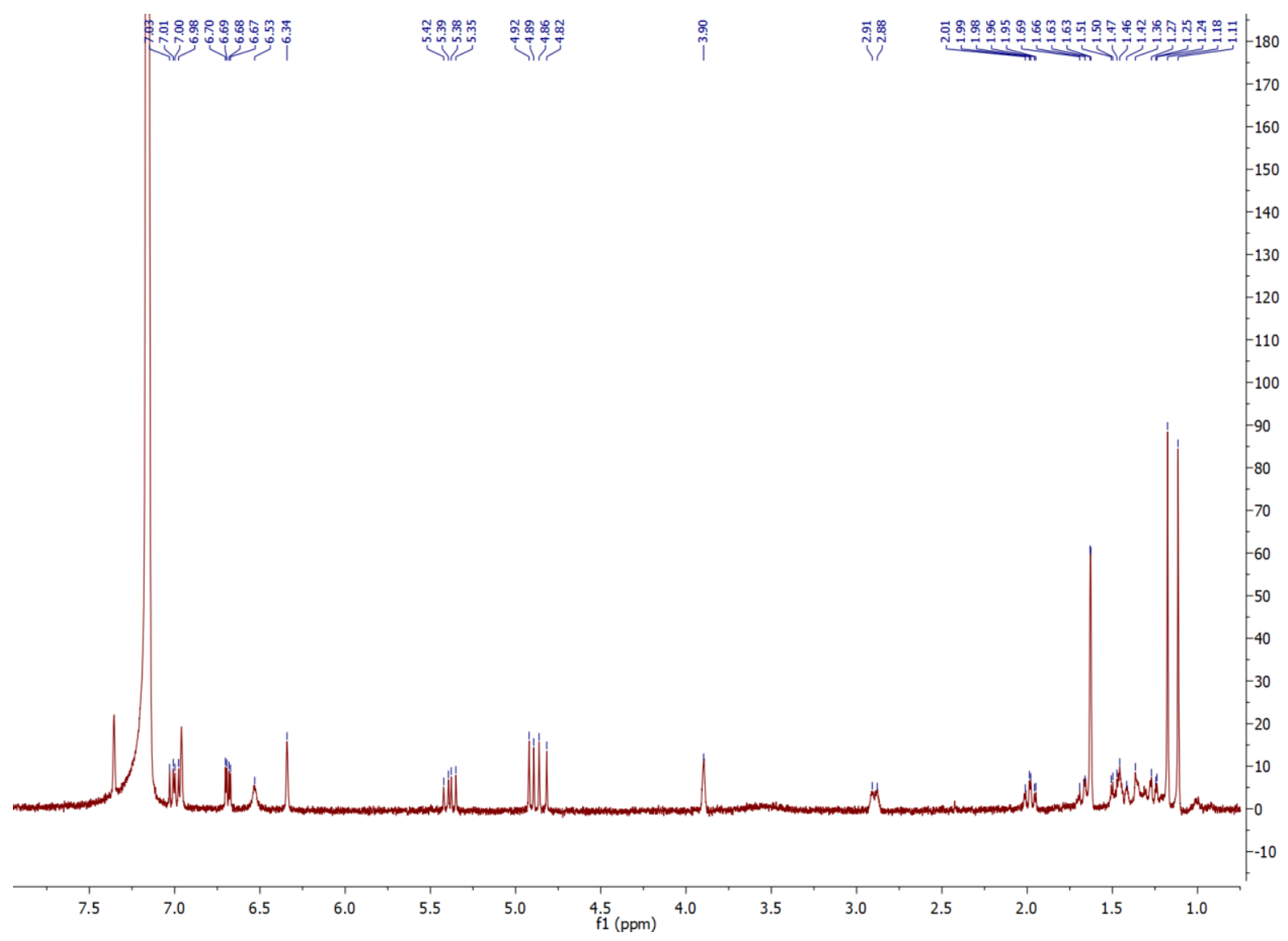




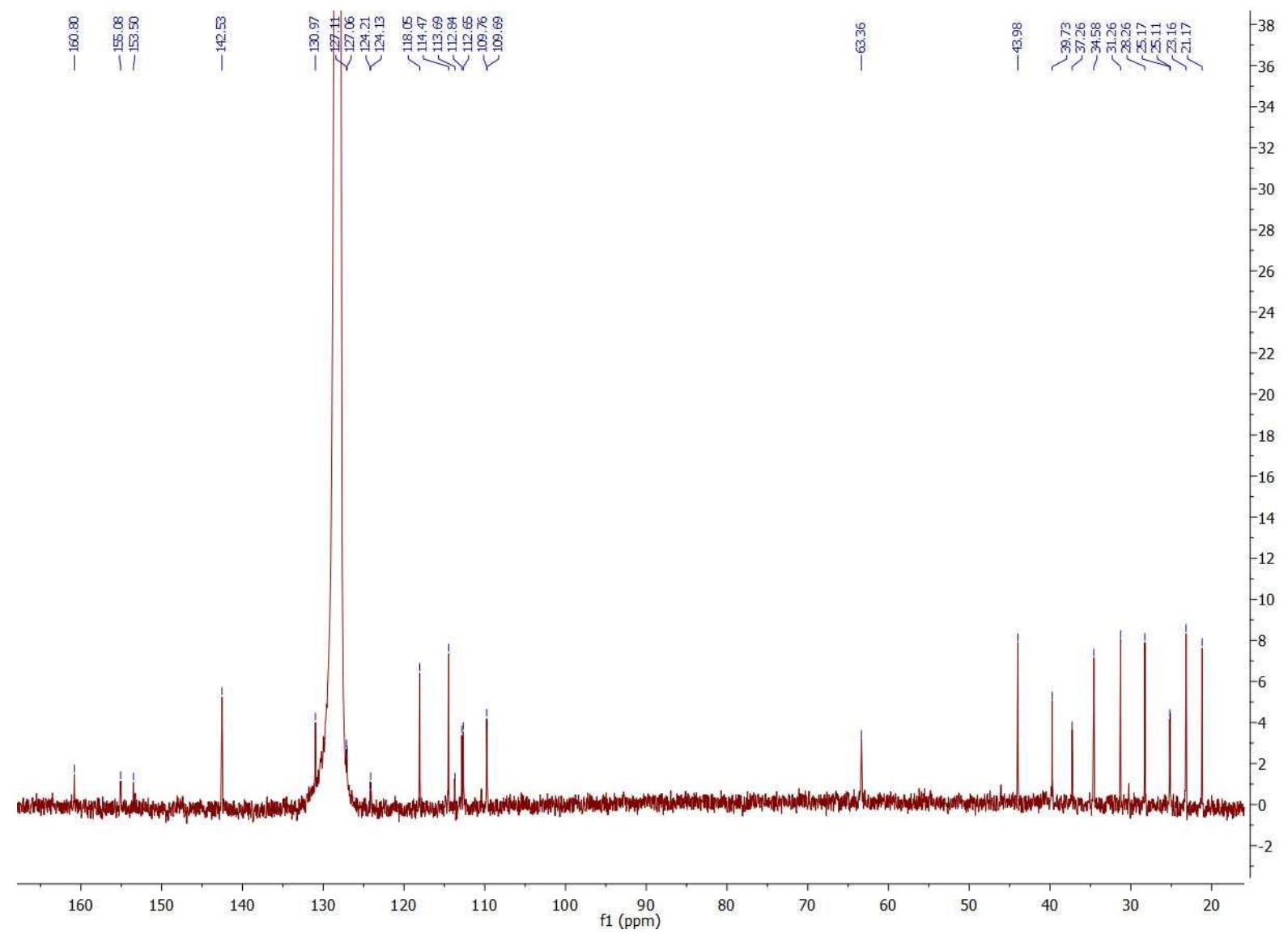




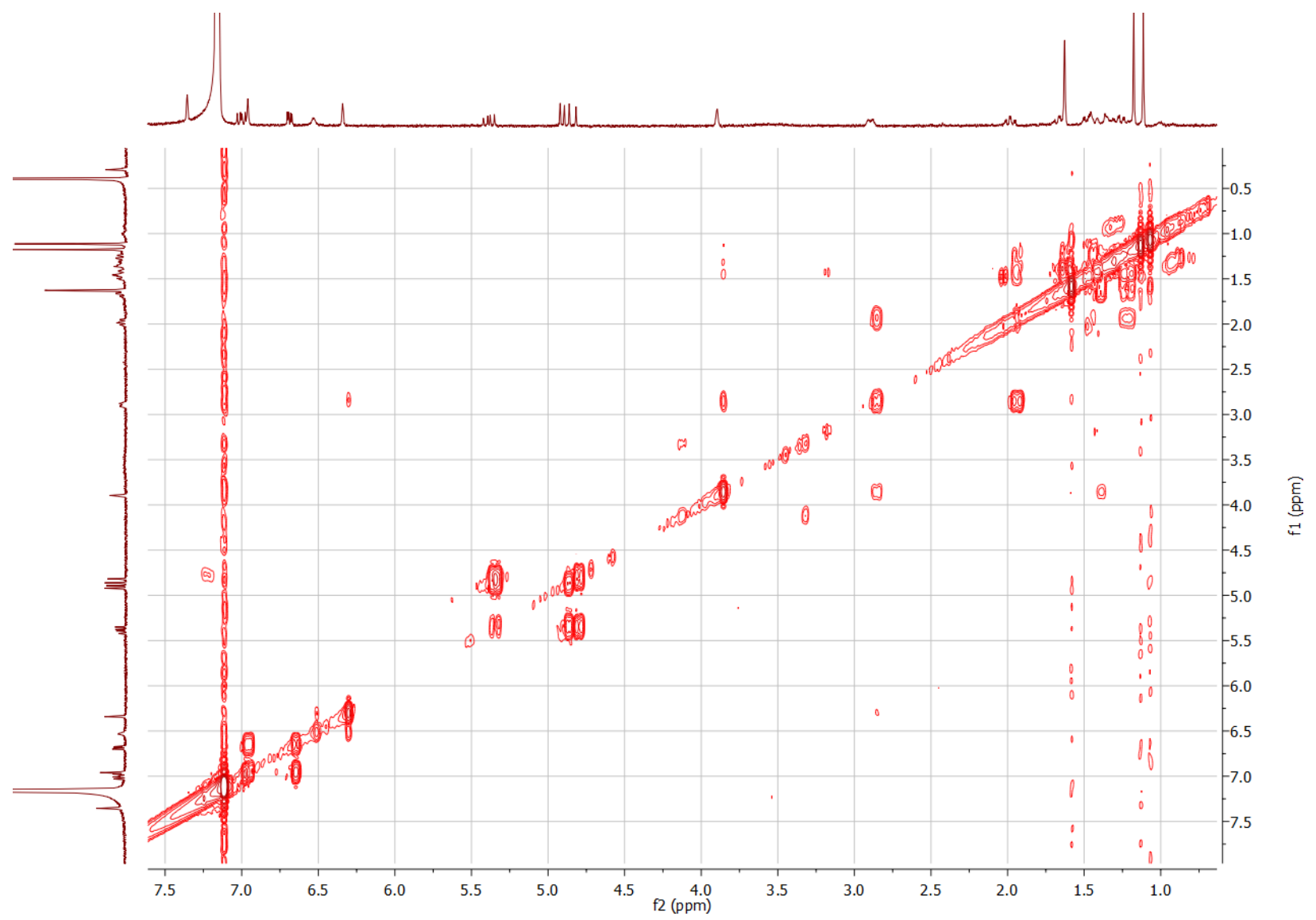




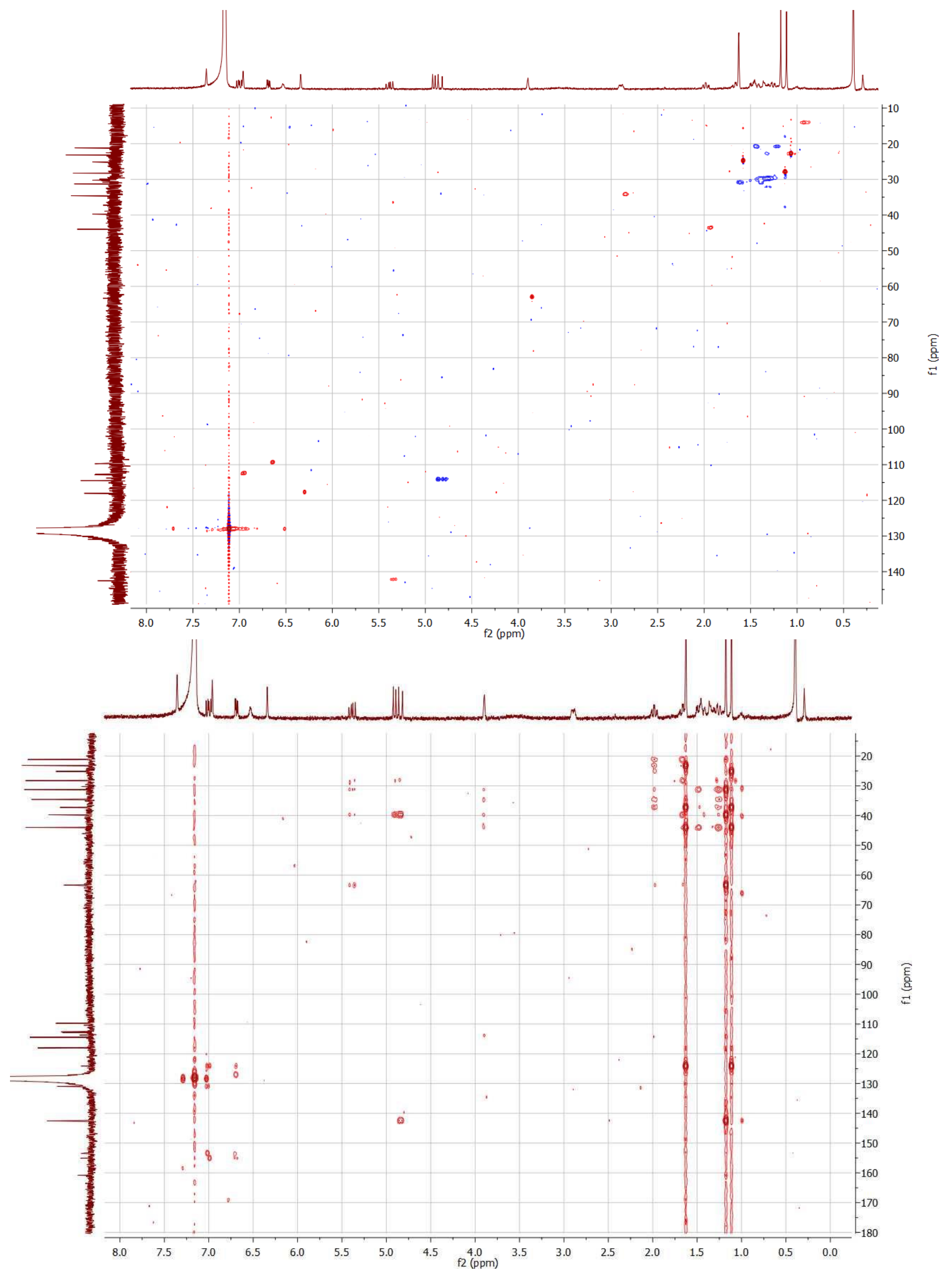




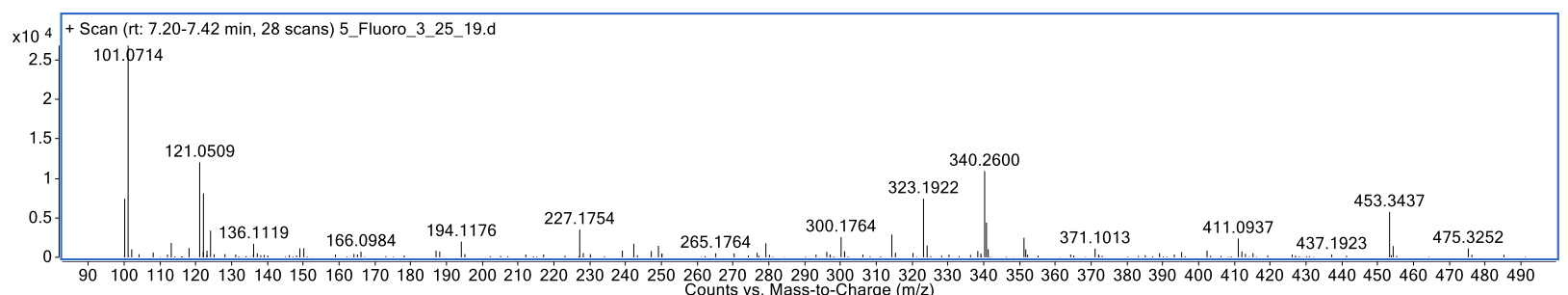

Calc. $[\mathrm{M}+\mathrm{H}]+$ 323.1918 Obsv. 323.1922 
Figure S4: Spectra of 6-fluoro-12-epi-hapalindole U (16)

${ }^{1} \mathrm{H},{ }^{13} \mathrm{C}$, COSY, HSQC, HMBC NMR spectra and HRMS of 6-F-12-epi-Hapalindole U 16 in $\mathrm{C}_{6} \mathrm{D}_{6}$ at 600 $\mathrm{MHz}$ for ${ }^{1} \mathrm{H}$ and COSY, $800 \mathrm{MHz}$ for HSQC and HMBC, and $201 \mathrm{MHz}$ respectively.

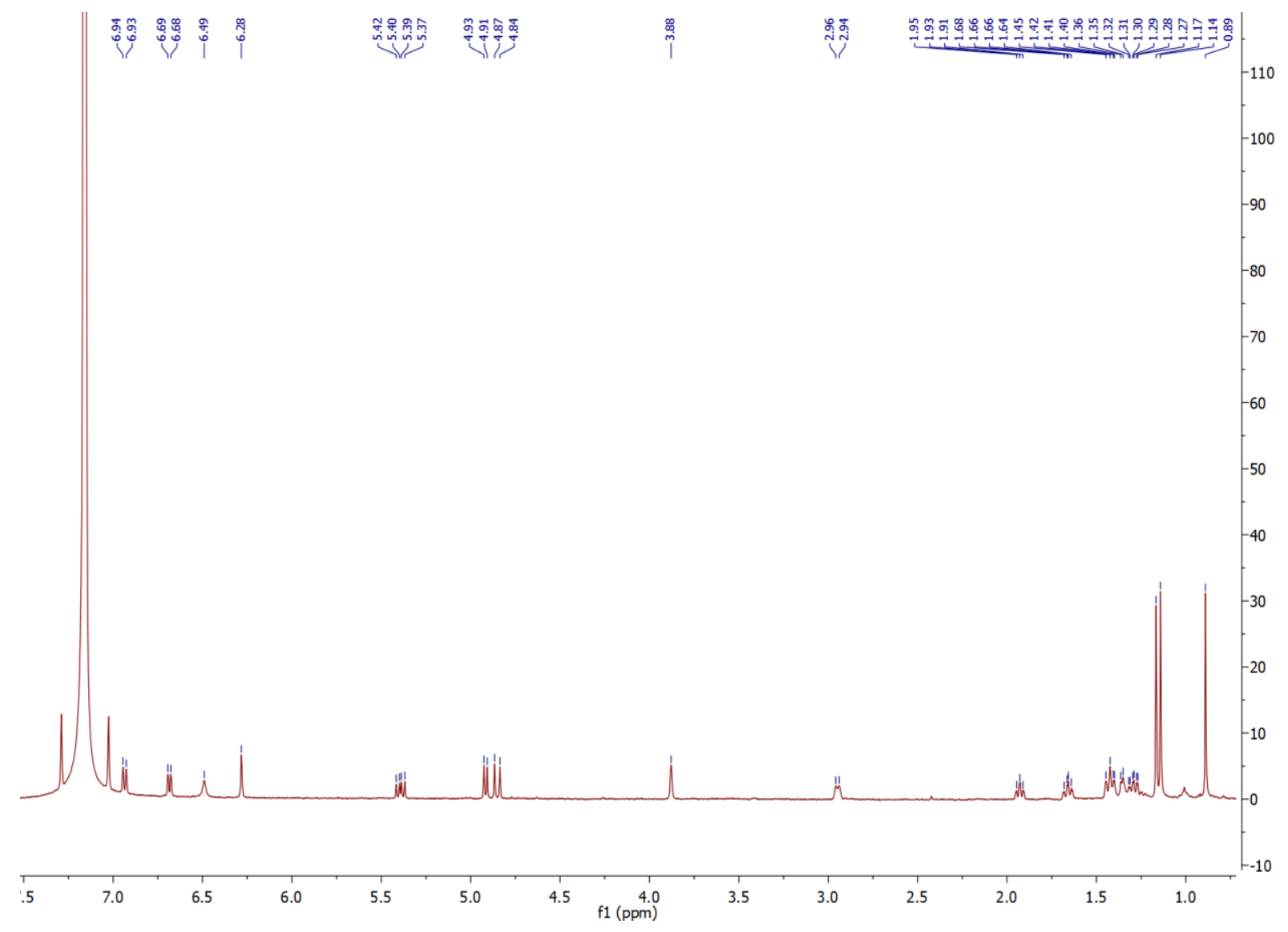




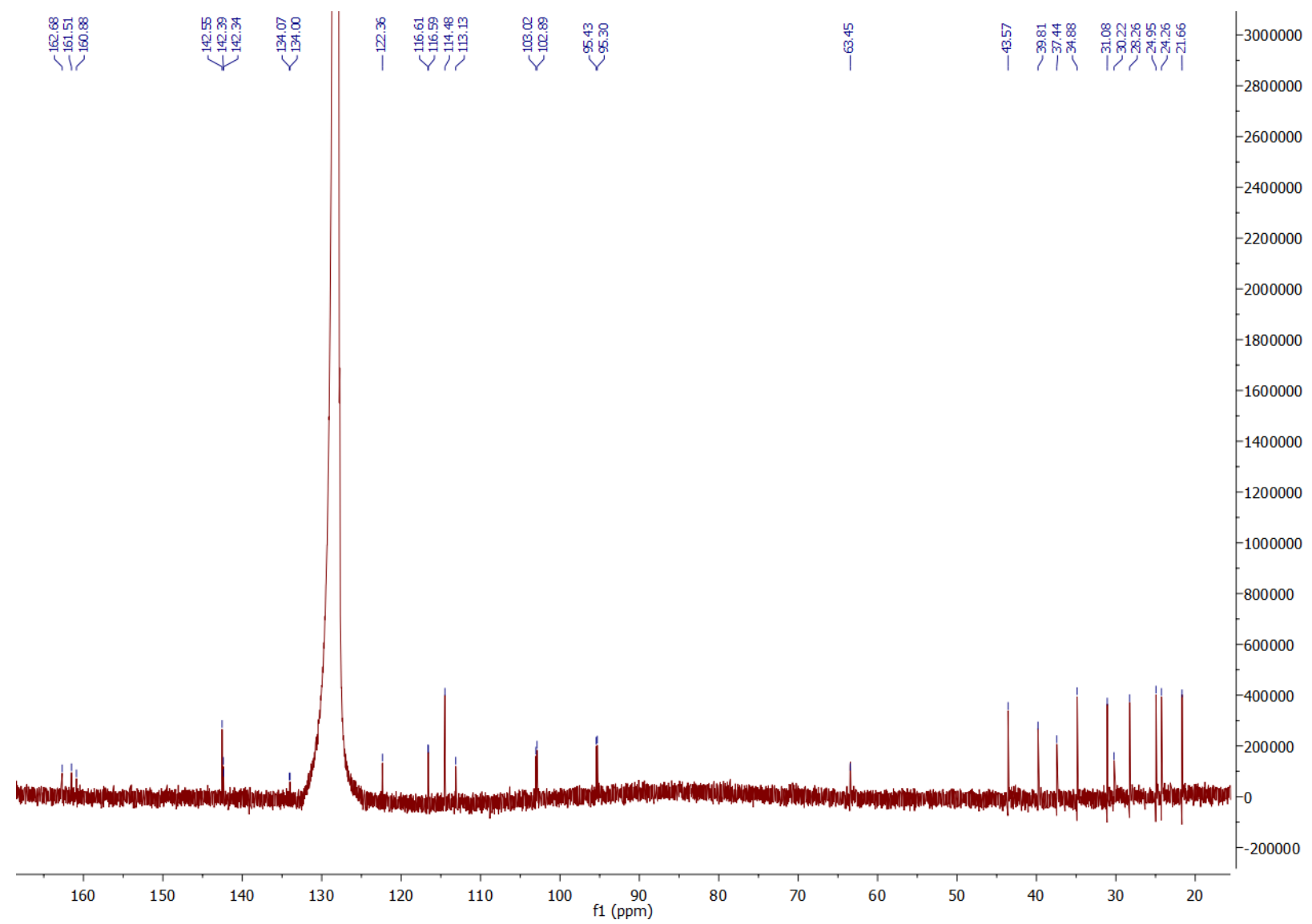



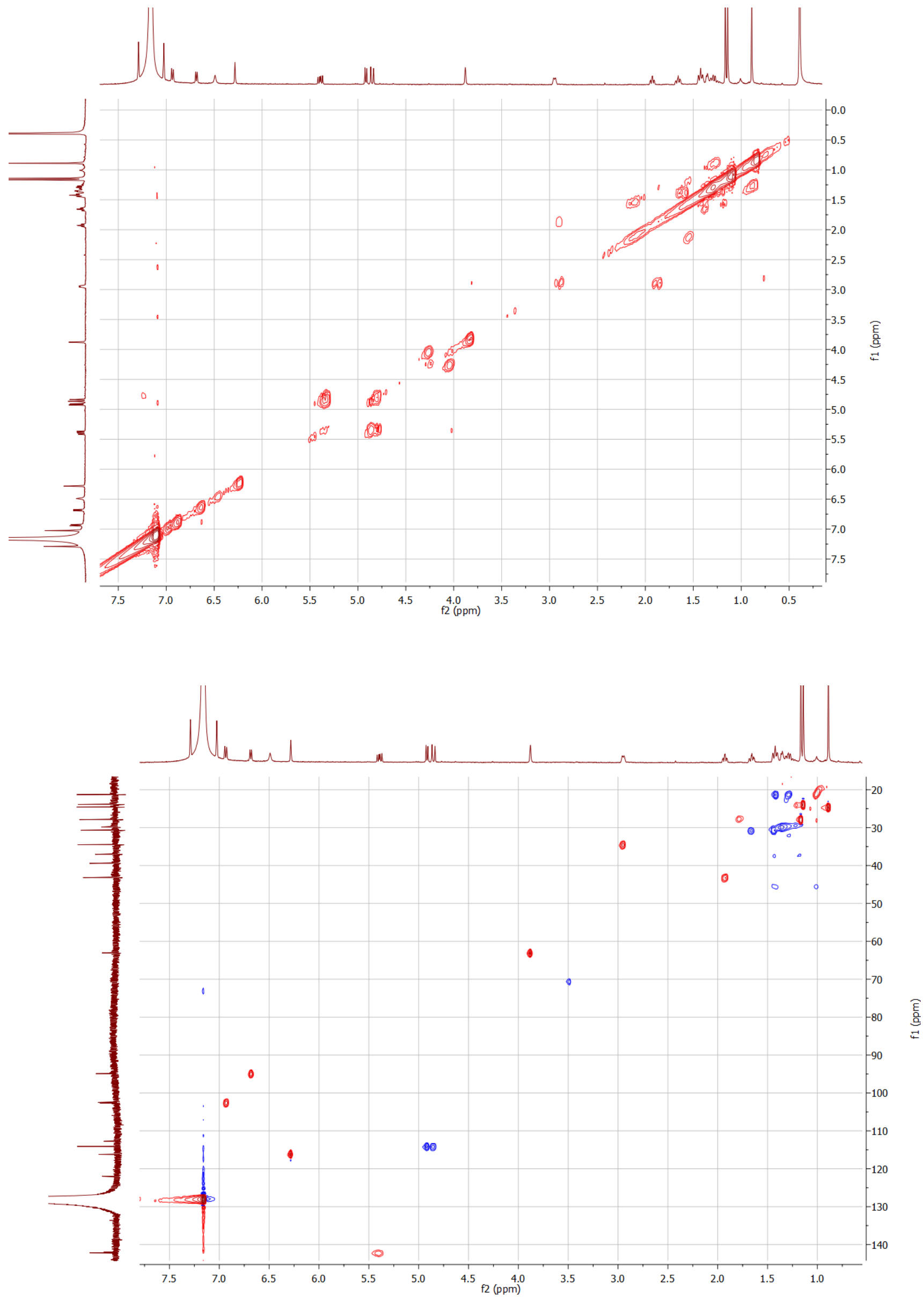


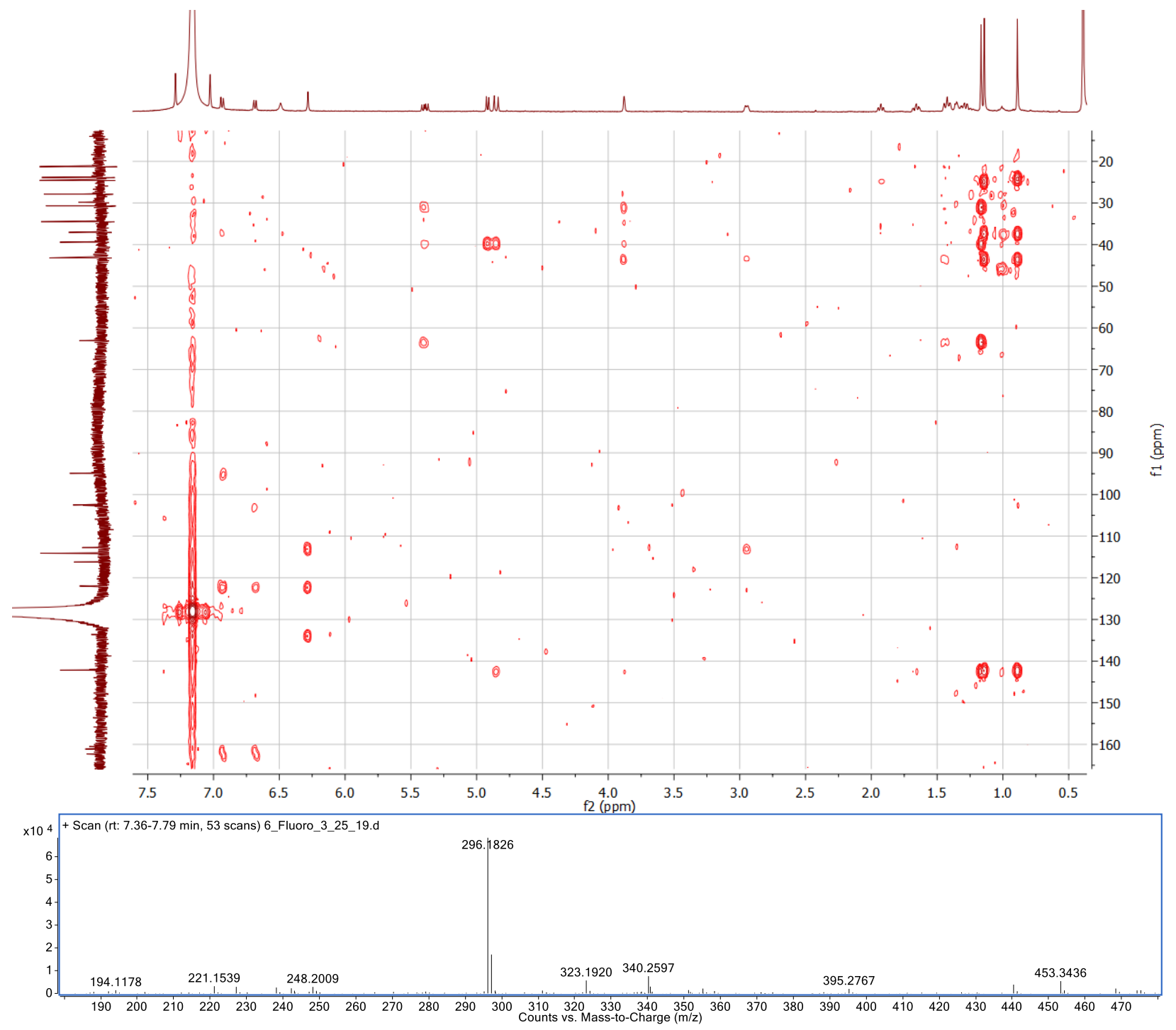

Calc. $[\mathrm{M}+\mathrm{H}]+{ }^{+} 323.1918$ Obsv. 323.1920 
Figure S5: Spectra of 5-fluoro-12-epi-fischerindole U (17)

${ }^{1} \mathrm{H},{ }^{13} \mathrm{C}$, COSY, HSQC, HMBC NMR spectra and HRMS of 5-F-12-epi-fischerindole $\mathrm{U} 17$ in $\mathrm{C}_{6} \mathrm{D}_{6}$ at 800 $\mathrm{MHZ}$ and $201 \mathrm{MHz}$ respectively.

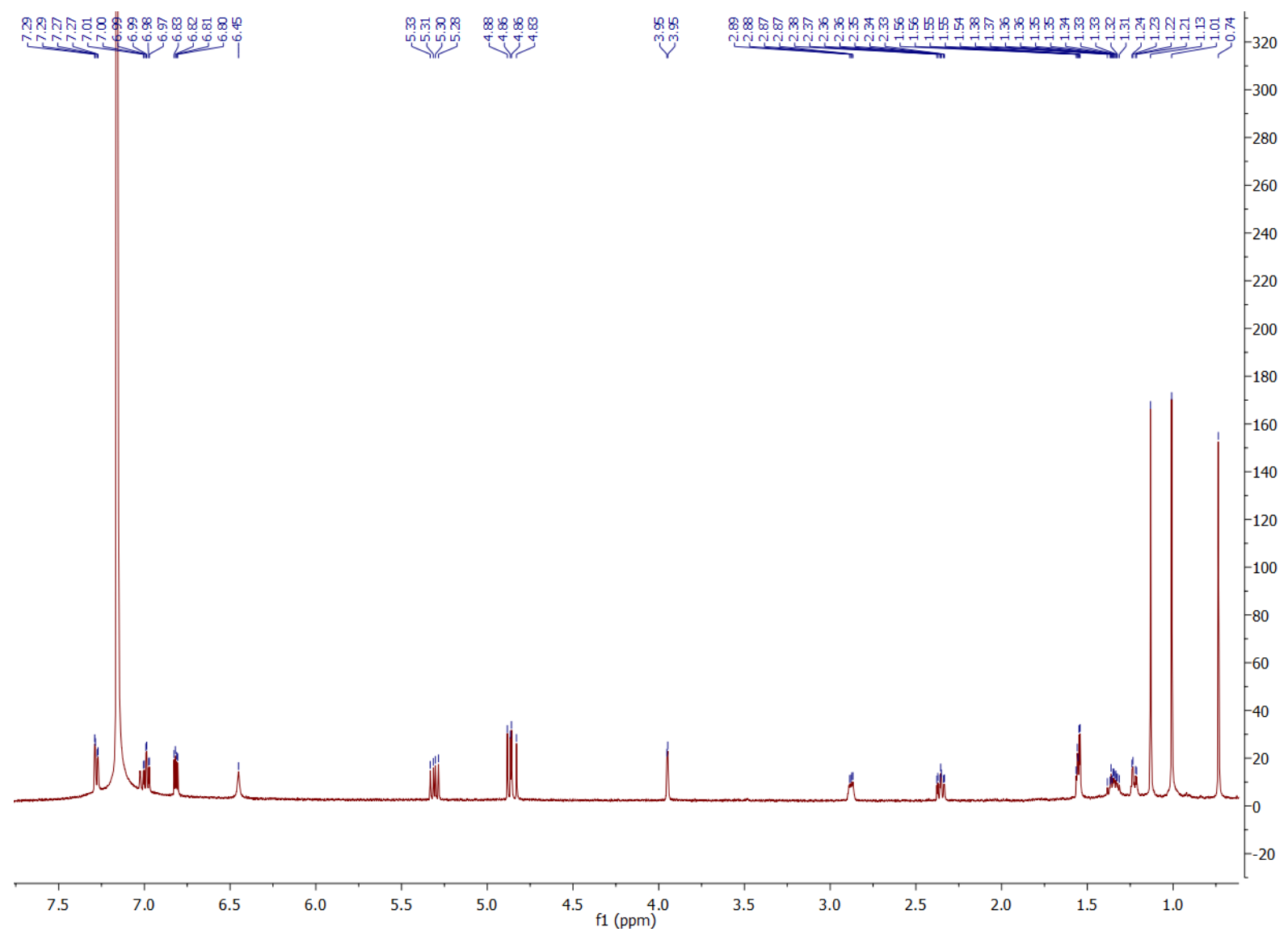




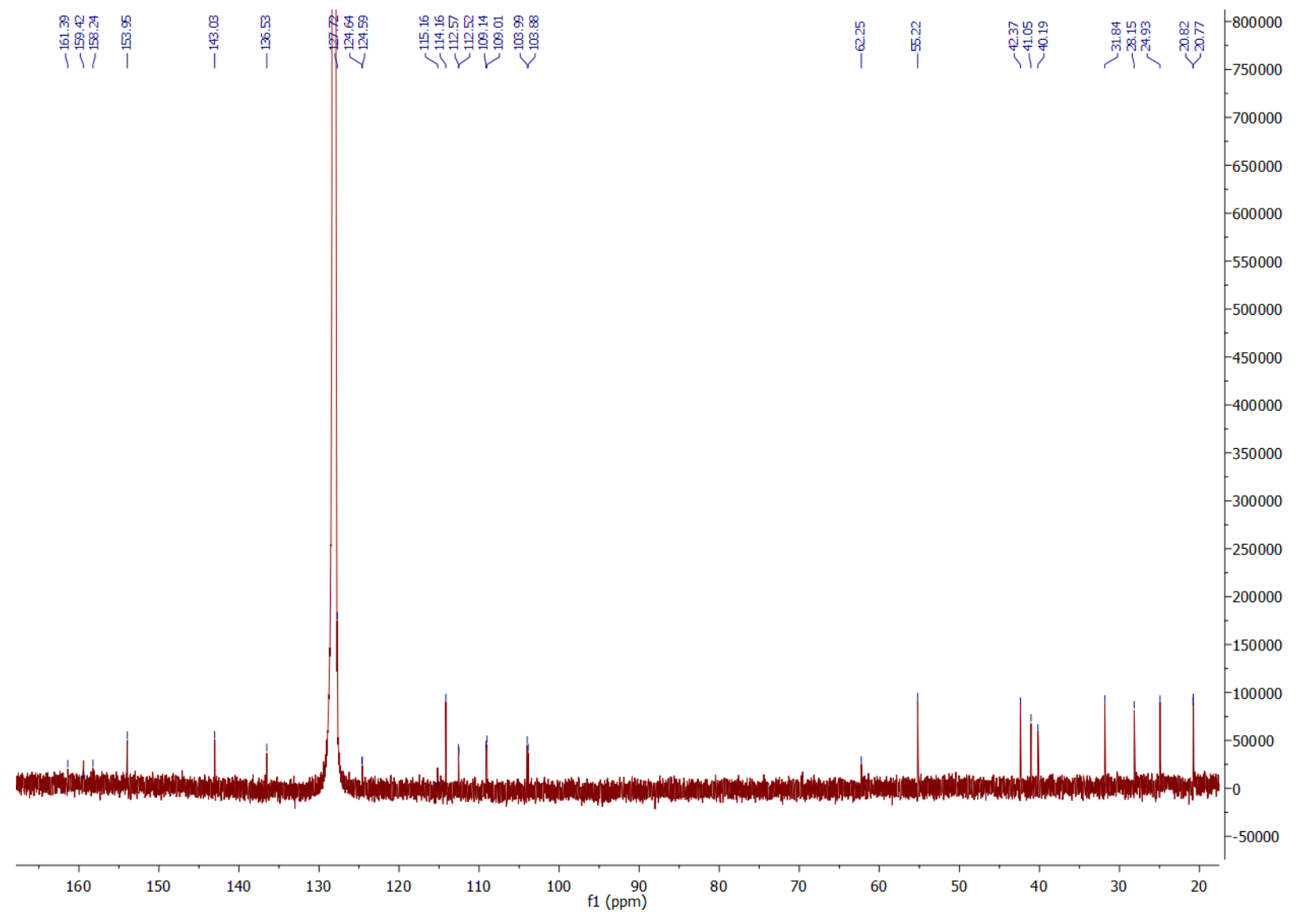



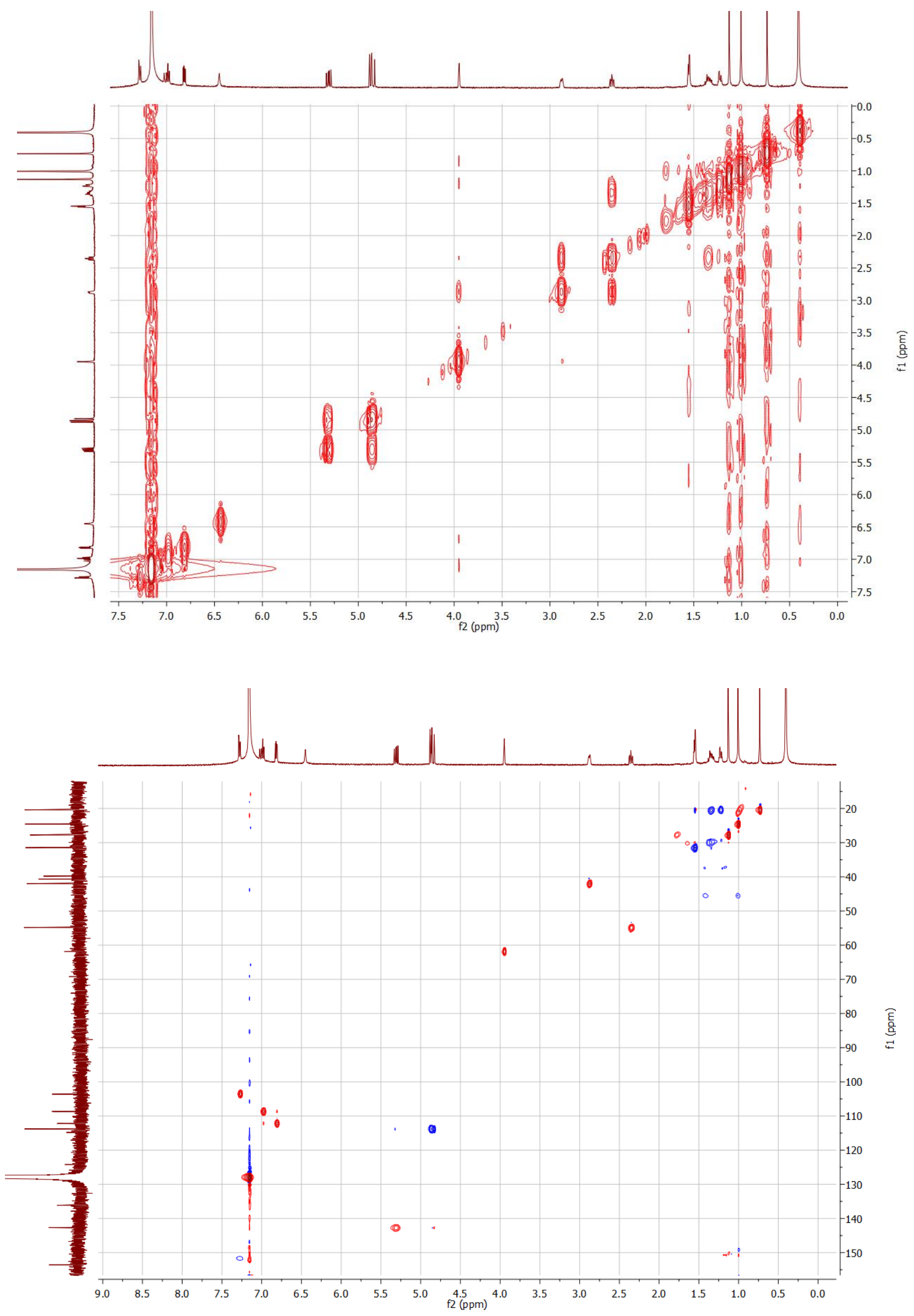

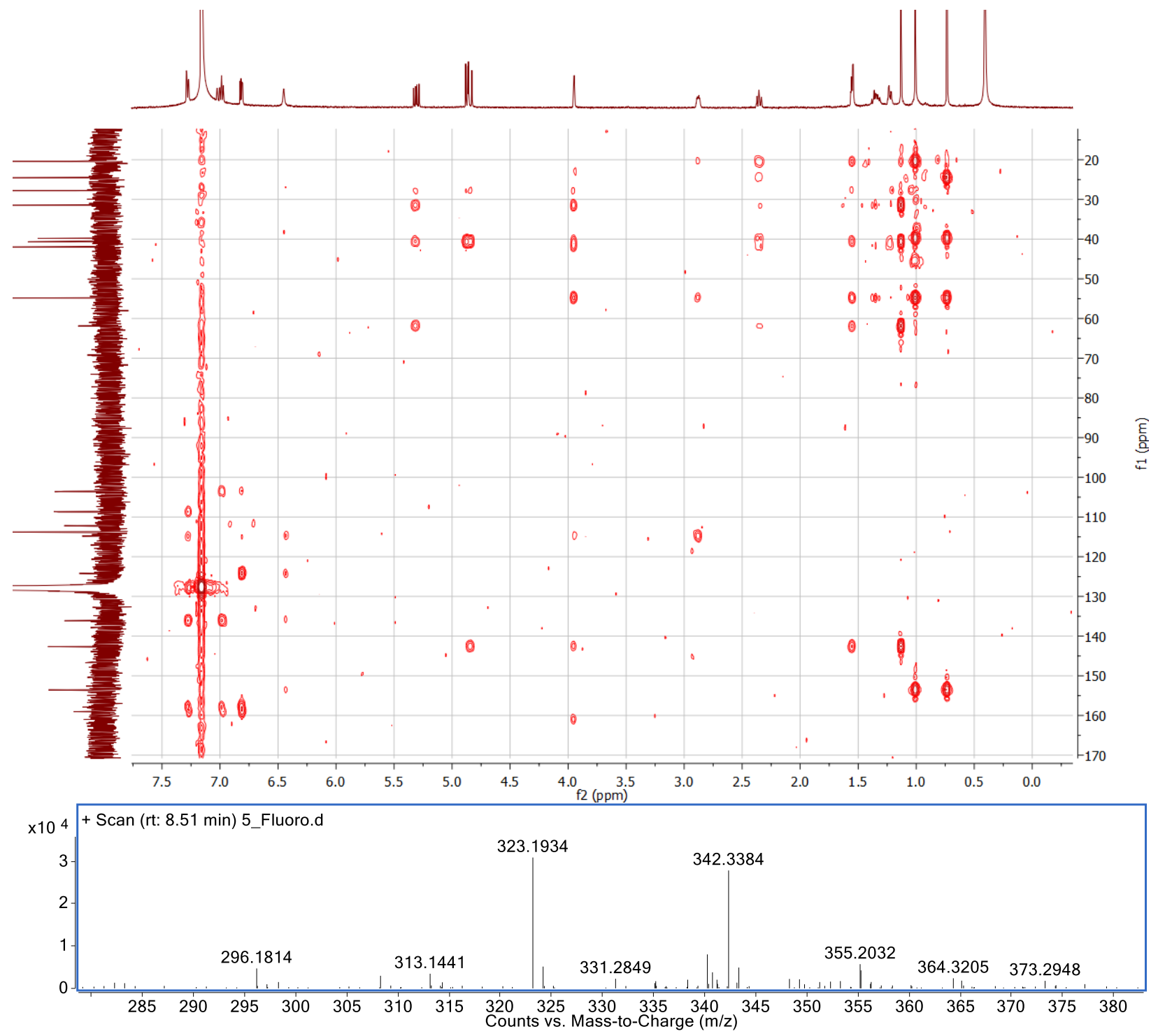

Calc. $[\mathrm{M}+\mathrm{H}]+323.1918$ Obsv. 323.1934 
Figure S6: Spectra of 6-fluoro-12-epi-fischerindole U (18)

${ }^{1} \mathrm{H},{ }^{13} \mathrm{C}$, COSY, HSQC, HMBC NMR spectra and HRMS of 6-F-12-epi-Fischerindole $\mathrm{U} 18$ in $\mathrm{C}_{6} \mathrm{D}_{6}$ at 600 $\mathrm{MHZ}$ and $125 \mathrm{MHz}$ respectively.

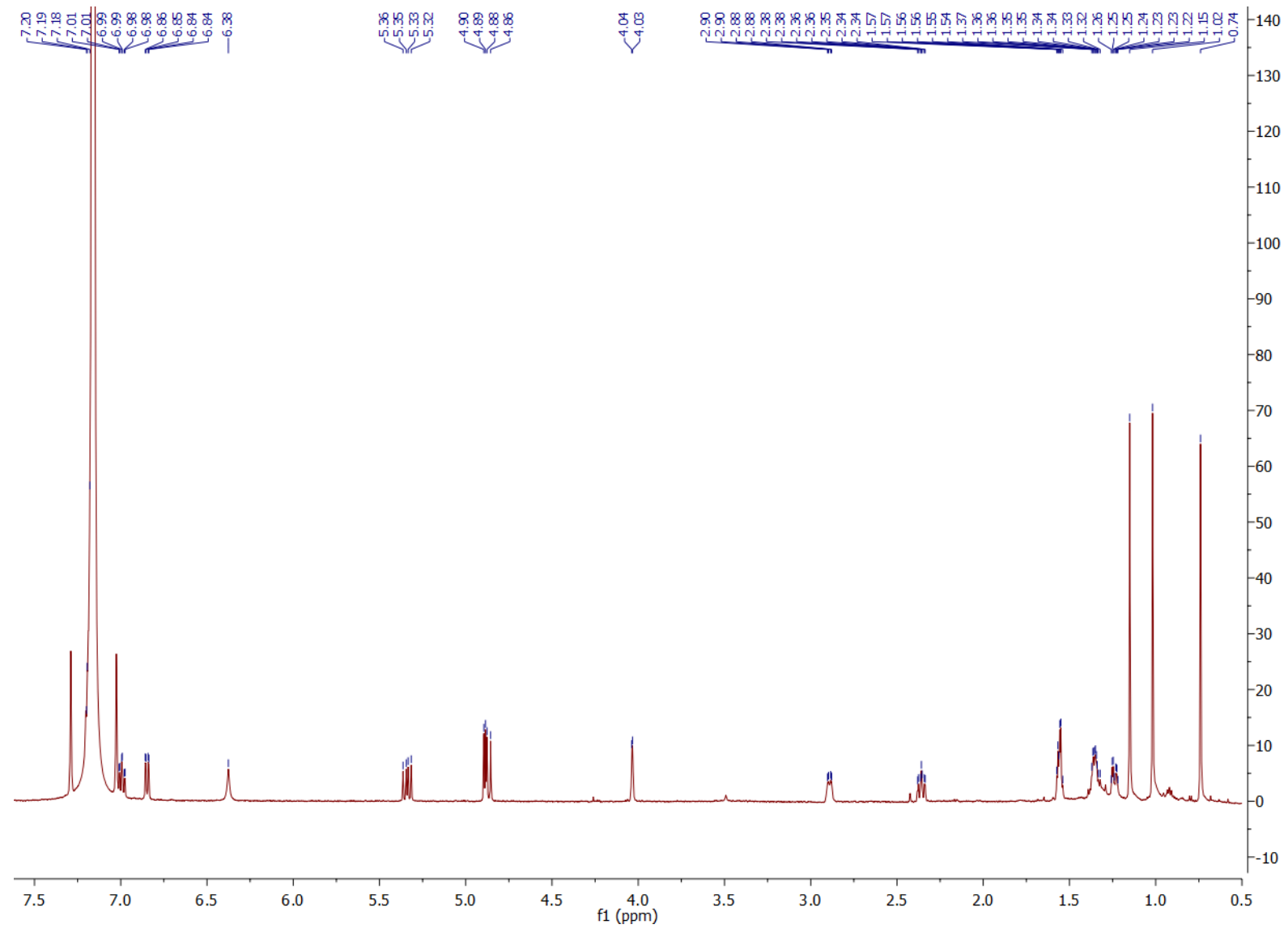




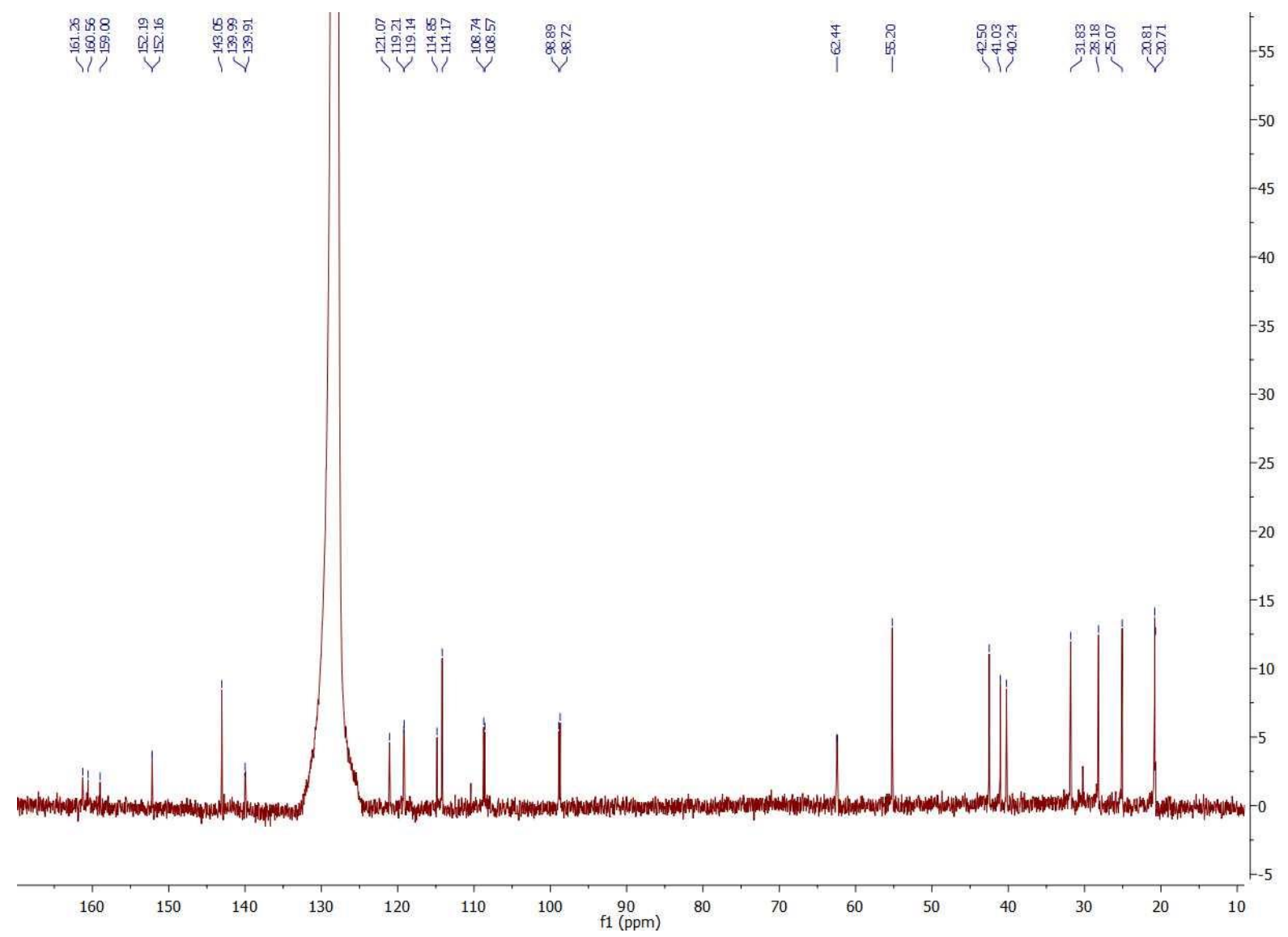



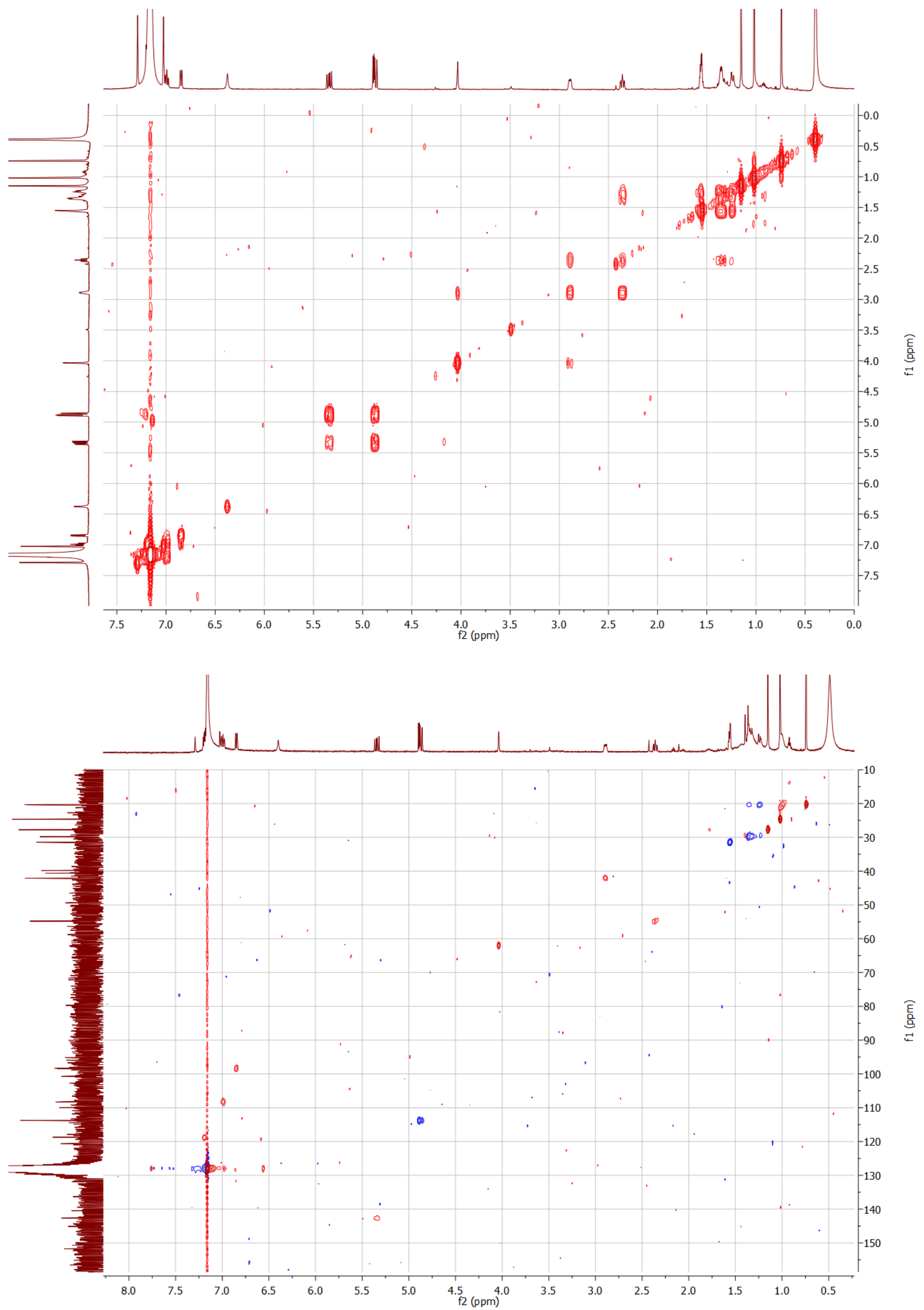

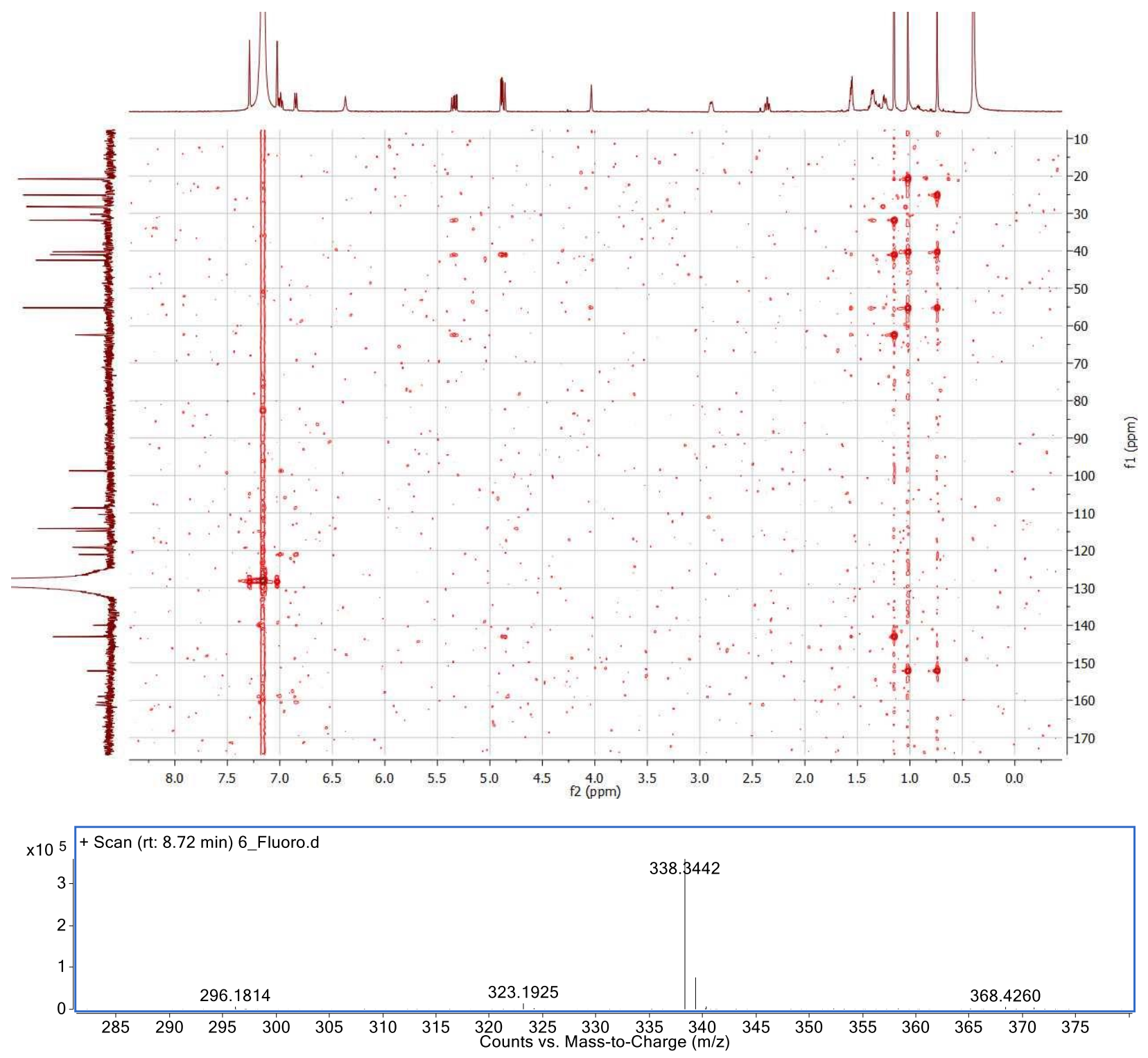

Calc. $[\mathrm{M}+\mathrm{H}]+323.1918$ Obsv. 323.1925 
Table S7: Amino acid sequences of cyclases

Protein Sequences

\section{FamC1}

MKRKLIVAVVFLIFICLGINTPAHATSAVSIPINNAGFENPFMDVVDDYTIDTPPGWTTYDPNNLVPEKRTT WTSNNGVGYVGPGTQFYNQLAPEGRNIGYIYLSQNPGSGVAGFEQILDATLEPDTKYTLTVDVGNLAGTF KGLSFAGFPGYRVELLAGDTVLAADHNNLFIKEGEFKTSTVTYTSTAKDLHLGQKLGIRLVNLLQDKFSGL DFDNVRLTTEPTET

\section{FamC2}

MKRNLIVAAIVLLIYICSGINTPANAAVTTSIPIKNPGFEEPILKVEGDYTIDAPPGWTTYNPNGLIPEKRTKW TSNNGVGHVGPNYGQLFYNQQLPEGKNIGFVYLAQKTGSGIAGFEQTLDAVLEPNTSYKLIVDIGNFGGMF KGVSFAGFPGYRVELLAGDTVLAADHNNLYIKDGEFKTSTVTFTSAANNPYLGQKLGIRLINLLQGKFSGL DFDNVRLITETVDT

\section{FamC3}

MKLKSIVAVVFLIFICLGINTPANATGAVSIPIKNAGFEDPFLEVKDYYTVNTPPGWSTYDPNGLIPEQPTVQ TSYVGVTNATPSSAFYDQKVPEGRNMGSVYLAHEPGSGIAGLEQTLDTVLESNKNYTLLVDIGNSADGYK DISLADFPGYRVELLAGDKVIAVDHNSVYIKEGEFKTSMIKFTAKPDSPYLGQKLGIRLINSLQTLSGNIDFD NVRLSVESAVI

FisC

MKRNFIIAAIVLLVYICFGISISANAASAVSIPIKNAGFEEPSLTVEDYYTIDTPPGWITYDPNGLVPAKRTRIT SNNGVGYTGPNSAYYNHKAPEGRNVAYVYLAQEIGSGIAGLEQTLDAVLKPNTKYTLTVDIGNSGGSFQG FPLDGFPGYRVELLAGDTVLAADQNNLYIKEKDFKTTTVTFIATPESPYLGQHLGIRLINPLQGKFSGVDFD NVRLTAEPAET

\section{FimC5}

MKRNFIIAAIVLLVYIFSGINVFANAASAVCIPIKNAGFEEPILQIEDDYTIDTPPGWITYDPGGLVPAKRTRIT SNNGVGYTGSNSEFYNHKAPEGRNVAFVYLAQEIGSGIAGLEQTLDAVLKPNTKYTLTVDIGNSGGSFQGK TLDGFPGYRIELLAGDTVLAADHNTLYIKEKDFKSTTVTFTATPESPYLGQHLGIRLINPLQGKFSGVDFDN VRLTAEPAET 